\title{
A cirrus cloud scheme for general circulation models
}

\author{
B. Kärcher* and U. Burkhardt \\ Deutsches Zentrum für Luft- und Raumfahrt, Institut für Physik der Atmosphäre, Oberpfaffenhofen, Germany
}

\begin{abstract}
A statistical cloud scheme for non-convective cirrus formed by homogeneous freezing of supercooled aerosols is presented. As large-scale cirrus clouds exhibit metastable thermodynamic states and have long lifetimes, a fully prognostic approach is developed. The scheme is based on separate probability distribution functions of total water representing clear-sky and in-cloud conditions. These distributions are based on in situ observations and have few degrees of freedom so that they can be used in forecast and climate models. Predictive equations are derived for horizontal cloud fraction and mixing ratios of grid-mean water vapour and ice water, in-cloud water vapour and ice crystal number. The scheme allows sub- and supersaturations with respect to ice to occur in cloud-free air and inside cirrus, and produces nucleated ice crystal concentrations and sizes in good agreement with observations, an important prerequisite for an improved treatment of cirrus cloud radiative properties. Implementation in general circulation models, open issues and future research avenues are discussed. Copyright (c) 2008 Royal Meteorological Society
\end{abstract}

KEY WORDS climate modelling; statistical cloud scheme; stratiform cirrus; weather forecast

Received 6 December 2007; Revised 28 April 2008; Accepted 30 June 2008

\section{Introduction}

Cirrus clouds have attracted considerable interest due to their impact on the Earth's climate (Stephens et al., 1990; Udelhofen and Hartmann, 1995; McFarquhar et al., 2000; Chen et al., 2000). These high-altitude $(8-18 \mathrm{~km})$ ice clouds exert a climate forcing mainly in the terrestrial radiation spectrum and constitute a significant uncertainty in global models simulating clouds and cloud-radiation feedbacks (Rasch and Kristjànnson, 1998; Zhang et al., 2005; Ringer et al., 2006). Much of the uncertainty arises from the numerous interactions and feedbacks between dynamical, microphysical and radiative processes affecting cirrus, which are poorly understood and poorly constrained by available data (Starr and Cox, 1985; Ou and Liou, 1995; Quante and Starr, 2002), or are debated controversially (Lindzen et al., 2001; Hartmann and Michelsen, 2002).

The model climate in general circulation models (GCMs) is sensitive to even small changes in the cirrus coverage, affecting weather forecasts and climate forcings (Lohmann and Kärcher, 2002; Tompkins et al., 2007). Tropical cirrus layers near the tropopause play a role in controlling the stratospheric water concentration by dehydration of air (Holton and Gettelman, 2001). Large ice crystals might fall into lower-level clouds, leading to glaciation, changing the precipitation efficiency (Herzegh and Hobbs, 1980), and thereby modifying the hydrological cycle. Cirrus cloud particles provide surfaces for uptake of nitrogen oxide reservoir species (Kärcher and

\footnotetext{
*Correspondence to: Bernd Kärcher, DLR, Institut für Physik der Atmosphäre, Oberpfaffenhofen, D-82234 Wessling, Germany.

E-mail: bernd.kaercher@dlr.de
}

Voigt, 2006) and possible heterogeneous chemical reactions involving halogens (Thornton et al., 2007), both affecting ozone, which is an efficient greenhouse gas in the troposphere (Lacis et al., 1990).

Despite decades of meteorological research, cirrus clouds remain very poorly characterised in global models. Reasons for the difficulty in understanding cirrus clouds and their atmospheric effects include the wide range of spatial and temporal scales of cirruscontrolling factors (DelGenio, 2002), the limitation of microphysical measurements because of the inaccessibility at high altitudes, and the complex nature of ice initiation (Cantrell and Heymsfield, 2005; Grabowski, 2006). Sound knowledge of cirrus microphysical properties would facilitate the use of cloud-resolving models in improving GCM parametrizations and improve retrieval algorithms employed to evaluate ground-based and spaceborne active and passive remote-sensing measurements. For cirrus in particular, GCM results cannot be accurately constrained by available satellite data (Zhang et al., 2005).

Unlike warm clouds composed of liquid water droplets that nucleate on suitable cloud condensation nuclei at small (tenths of percent) water supersaturations, ice crystal formation in cold cirrus clouds requires substantial (tens of percent) ice supersaturations. Cloud schemes in global models that are based on ice crystal formation at saturation and saturation adjustment within the cloud, i.e. the immediate conversion of supersaturation into condensate mass, are not consistent with the cirrus formation process (Kärcher and Lohmann, 2002). Likewise, cloud ice may not evaporate instantaneously (within a GCM time step), as large ice crystals are known to survive in subsaturated air at low temperatures (Hall and 
Pruppacher, 1976). To model cirrus formation and decay properly in a GCM, a prognostic treatment of cloud fraction, humidity, and ice variables is necessary. Another reason in support of a prognostic approach is the relatively long lifetime of large-scale cirrus (Tiedtke, 1993) and the fact that the lifetime of such layer clouds can be prolonged by ice-radiation feedbacks, depending on cloud environmental static stability (Köhler, 1999; Dobbie and Jonas, 2001).

Ice microphysical processes require at least knowledge of subgrid-scale fluctuations of temperature, humidity, and updraught velocities. These fluctuations are not taken into consideration when defining cloud fraction based solely on relative humidity (Walcek, 1992, and references therein; Teixeira, 2001). Therefore, simple cloud coverage parametrizations without explicit reference to subgridscale variability are not consistent with known ice microphysics. Statistical cloud schemes based on probability distribution functions (PDFs) of total water and other variables that provide this information explicitly still treat the ice phase in cirrus clouds similarly to liquid water clouds (Smith, 1990; Ricard and Royer, 1993; Tompkins, 2002), applying saturation adjustment. An operational scheme that predicts cloud fraction and cloud condensate (Tiedtke, 1993) relies on clear-sky humidity fluctuations that are uniformly distributed with a time-independent variance and is therefore equivalent to a simple relative humidity scheme in which the onset of cloud formation is dictated by a fixed relative humidity threshold (Gregory et al., 2002).

The current model version of the European Centre for Medium-Range Weather Forecasts (ECMWF) Integrated Forecast System predicts ice supersaturation consistent with a prognostic cloud fraction, but relies on highly simplified ice microphysics and applies saturation adjustment in cloudy air (Tompkins et al., 2007). A version of the ECHAM (ECMWF model, Hamburg version) climate model considers advanced ice microphysics for cirrus formation and growth allowing grid-scale supersaturation, but uses a relative humidity-based diagnostic cloud fraction that is ignorant of supersaturation and assumes equal humidity inside and outside of cirrus clouds (Lohmann and Kärcher, 2002). An approach similar to ECHAM has been adopted in the National Center for Atmospheric Research (NCAR) Community Atmospheric Model (Liu et al., 2007). Gettelman and Kinnison (2007) imposed bulk upper-tropospheric ice supersaturation in the Whole Atmosphere Community Climate Model (WACCM) by modifying the relative humidity-based diagnostic cloud fraction such that clouds form (or disappear) at $110 \%$ and full cloud coverage is reached at $120 \%$ relative humidity. These authors acknowledge that their attempt to explore the impact of supersaturation on radiative forcing does not realistically model supersaturated states and cirrus cloud fraction.

The aim of our paper is to present for the first time a process-oriented cirrus cloud scheme. Cirrus cloud fraction and cirrus-controlling microphysical processes are linked in a self-consistent theoretical framework and are driven by the same dynamical forcing. The analysis of Gregory et al. (2002) has shown that a prognostic approach to cloud parametrization that retains the concept of subgrid-scale variability resembles that of Tiedtke (1993) with certain modifications. Our scheme represents such an approach. It integrates all processes noted above that distinguish cirrus from other cloud types and which render the straightforward application of traditional cloud schemes to cirrus impossible without violating basic observational evidence. Contrary to the Tiedke scheme, which provides no information on humidity variability nor derives source and sink terms for cloud properties consistently with an underlying total water PDF (Jakob, 2000; Larson, 2004), we base the cirrus processes on explicit total water distributions. To construct such distributions, we seek guidance from in situ measurements of relative humidity and ice water content.

In section 2, we present the prerequisites needed to represent stratiform cirrus clouds in a GCM. In section 3, we describe the cloud scheme and derive its basic equations. In section 4 , we explicitly solve the cloud equations for an isolated air parcel and discuss the basic features of cirrus formation and dissipation. Aspects of implementation of our scheme into a GCM and open issues that warrant further research are elucidated in section 5. While short summaries of our main points are given at the end of most subsections, we provide an overall summary in section 6 . The appendix provides further material and includes a list of symbols.

\section{Prerequisites}

\subsection{Homogeneous freezing and initial growth}

Homogeneous freezing denotes the formation of the ice phase by stochastic ice nucleation in supercooled aerosol particles. These liquid particles contain water and various solutes, predominantly sulphuric acid and organics, that lead to a strong freezing point depression. In equilibrium with ambient water vapour $\left(\mathrm{H}_{2} \mathrm{O}\right)$, a particle with a typical radius $r_{\mathrm{p}}=0.25 \mu \mathrm{m}$ freezes homogeneously within $1 \mathrm{~s}$ at an air temperature $T(\mathrm{~K})$, when the saturation ratio with respect to ice, $S$, exceeds the threshold (Koop et al., 2000; Ren and MacKenzie, 2005)

$$
S_{\mathrm{cr}}(T)=2.349-\frac{T}{259} .
$$

Equation (1) implies that air parcels acquire high ice supersaturations $S-1>0.44$ prior to freezing at temperatures below $235 \mathrm{~K}$. Values of $S_{\mathrm{cr}}$ for smaller (larger) particles are slightly higher (lower), and the sensitivity of the results presented in this paper to changes in $r_{\mathrm{p}}$ is small. In the upper troposphere and lowermost stratosphere, homogeneous freezing is a major pathway to form cirrus clouds in situ globally below the spontaneous freezing temperature of pure water droplets $(\sim 235 \mathrm{~K})$. This is demonstrated by a plethora of observations showing the frequent occurrence of high clear-sky ice supersaturation in conjunction with high number densities of ice crystals in cirrus clouds (Jensen et al., 2001; DeMott et al., 2003; 
Haag et al., 2003; Cziczo et al., 2004; Law et al., 2006, and references therein).

Aircraft measurements of number concentrations of small ice crystals in the generation zone of cirrus should be relatively accurate (within a factor of two), because the absence of large $(>100 \mu \mathrm{m})$ crystals minimizes shattering artifacts known to affect optical particle probes (Gayet et al., 2002). Observed total number densities $n$ of cirrus ice crystals formed by homogeneous freezing are $0.1-10 \mathrm{~cm}^{-3}$ (Kärcher and Ström, 2003; Gayet et al., 2004; Hoyle et al., 2005). This is only a small fraction of the total aerosol number density $n_{\mathrm{p}}$, but well above the background concentrations of heterogeneous ice nuclei possibly available at cirrus altitudes (DeMott et al., 2003; Haag et al., 2003). Processes such as turbulence, sedimentation, aggregation and sublimation act to reduce the high concentrations while the cloud further develops.

In an adiabatically rising air parcel, the competition between generating supersaturation by cooling and removing supersaturation by diffusional growth of the newly formed ice crystals determines the microphysical properties of young cirrus clouds. The homogeneous freezing process and the initial growth phase can be accurately tracked by means of an analytical parametrization scheme (Kärcher and Lohmann, 2002). Specifying aerosol size distribution, absolute value of the cooling rate $\omega=|\mathrm{d} T / \mathrm{d} t|$, air pressure $p, T$, and $S$ as input, the scheme returns $n$, the mean radius $r$ of the nucleated ice crystals, and the remaining supersaturation after a specified time interval $\Delta t$.

We show selected results from this scheme in Figure 1 as a function of $\omega$ for combinations of $p$ and $T$ representing cirrus formation at cold, warm, and intermediate conditions. We present $n$ and the time-scales $\tau_{\mathrm{f}}$ measuring the duration of the freezing event, $\tau_{S}$ determining how long the supersaturation $\left(S_{\mathrm{cr}}-1\right)$ lasts after freezing, and $\tau_{\mathrm{g}}$ determining how fast the new ice crystals

(a)

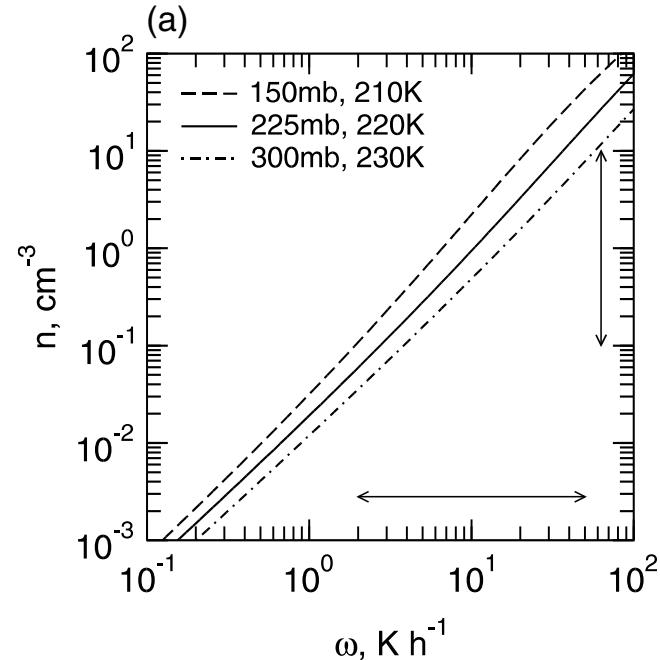

grow and begin to deplete the $\mathrm{H}_{2} \mathrm{O}$ vapour. To a good approximation, monodisperse particles with radii $r_{\mathrm{p}}=$ $0.25 \mu \mathrm{m}$ and $n_{\mathrm{p}}=500 \mathrm{~cm}^{-3}$ can be assumed (common upper-tropospheric values), because these results are only weakly sensitive to details of the freezing aerosol size distribution. We discuss the time-scales and ice crystal properties originating from freezing of monodisperse aerosols further in Appendix A.

At a given $\omega$, Figure 1(a) shows that $n$ rises when $T$ decreases. Slower growth of the nucleated ice crystals at low $T$ causes $S$ to decrease at a slower pace, prolonging the time span where homogeneous freezing is active. The key feature, however, is the strong increase of $n$ with $\omega$. Faster cooling sustains high supersaturations and allows more crystals to form. This increase is stronger than in liquid clouds, making cirrus formation more susceptible to small dynamical changes than in lower-level clouds. The marked dependence of $n$ on $\omega$ is supported by laboratory (Möhler et al., 2003) and field (Gayet et al., 2006) studies of homogeneous ice formation, the latter implying that water vapour variability is not a controlling factor for ice initiation. The approximate scaling law $n \propto$ $\omega^{3 / 2}$ (Appendix A) will be of further use in section 2.2. Moderate deviations from that scaling occurs for $\omega>$ $50 \mathrm{~K} \mathrm{~h}^{-1}$ and $T<210 \mathrm{~K}$. Here, freezing of particles smaller than $r_{\mathrm{p}}$ might lead to slightly higher $n$ values, because smaller particles need longer time to remove the supersaturation.

In Figure 1(b), the freezing time $\tau_{\mathrm{f}}$ is only weakly dependent on $T$, for which reason we only show the result for $220 \mathrm{~K}$. Homogeneous freezing occurs rapidly, as $\tau_{\mathrm{f}}<7 \mathrm{~min}$ even for the lowest cooling rates, and is always much shorter than $\tau_{S}$. The latter time-scale is inversely proportional to $n \widehat{r}$, where $\widehat{r}$ is the radius the ice crystals achieve after freezing (at $\tau_{\mathrm{f}}$ ). With $\omega=10 \mathrm{~K} \mathrm{~h}^{-1}$, we have $\tau_{S}=7-17 \mathrm{~min}$, implying that this growth phase

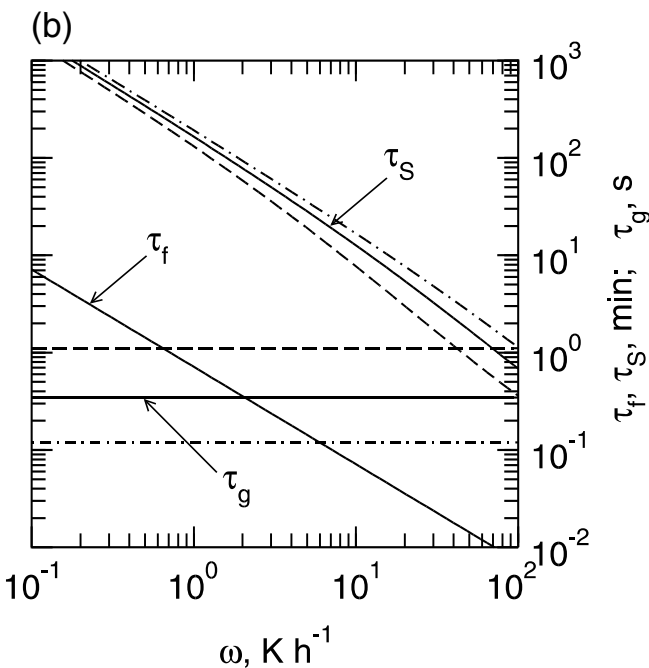

Figure 1. (a) Initial number density $n$ of ice crystals formed by homogeneous freezing of aerosol particles with $r_{\mathrm{p}}=0.25 \mu \mathrm{m}$ and (b) time-scales $\tau_{\mathrm{f}}(\mathrm{min})$ of the freezing events, $\tau_{S}(\mathrm{~min})$ of the initial decay of $S$, and $\tau_{\mathrm{g}}$ (s) of the initial growth of the new ice particles, both versus the adiabatic cooling rate $\omega$. Freezing pressures and temperatures are given in the legend. Arrows in (a) mark the range of observed values of $n$ and a range of $\omega$ that agree well with the observed range leading to these concentrations. A value of $10 \mathrm{Kh}^{-1}$ is equivalent to an updraught speed of $\sim 30 \mathrm{~cm} \mathrm{~s}^{-1}$ 
is shorter than, or comparable to, the time steps used in large-scale models (10-60 min).

The initial growth of the small crystals is faster than freezing in many cases $\left(\tau_{\mathrm{g}}<\tau_{\mathrm{f}}\right)$, but $\tau_{\mathrm{f}}$ may become comparable to $\tau_{\mathrm{g}}$ for high $\omega$ and low $T$. For the highest cooling rates and the lowest temperature shown in Figure 1, the new crystals remain relatively small right after freezing $\left(\widehat{r} \gtrsim r_{\mathrm{p}}\right)$ and their size begins to affect the evolution of $S$, causing the deviations from the 3/2-scaling.

In summary, the observed values of $n$ (vertical arrow in Figure 1(a)) translate into a range of cooling rates $2-50 \mathrm{~K} \mathrm{~h}^{-1}$ (horizontal arrow) that appear to determine the properties of young cirrus. In this region, effects of aerosol size and number on $n$ are small.

\subsection{Mesoscale temperature fluctuations}

The strong dependence of $n$ on $\omega$, with $\omega$ values by far exceeding typical synoptic values of the order $1 \mathrm{Kd}^{-1}$, strongly suggests that cirrus formation is sensitive to changes in the variability of vertical air motion on spatial and temporal scales unresolved by global atmospheric models (Kärcher and Ström, 2003). Remote sensing and in situ studies (Sassen et al., 1989; Mace et al., 2001; Whiteway et al., 2004) and numerical simulations (Haag and Kärcher, 2004) support this notion, but also confirm that synoptic-scale processes define the overall meteorological conditions in which cirrus formation and decay take place.

Observed fluctuations of temperature on the mesoscale (MTFs), that explain the high ice crystal number concentrations (section 2.1), cover horizontal length-scales $\ell=1-100 \mathrm{~km}$ (Ström et al., 1997; Bacmeister et al., 1999) and arise from a variety of sources. These sources include intense gravity waves released by mesoscale convective systems, high-amplitude lee waves induced by high mountain ridges, or in the area of jet streams and storm tracks. For instance, it has been pointed out that a lack of representation of gravity wave generation by subgridscale orography causes many GCMs to simulate insufficient amounts of high-cloud coverage over land (Dean et al., 2005). Even away from main source areas, there appears to be a persistent background of MTF driven by mesoscale gravity waves (Gary, 2006). The origin of these MTFs is not well known, but thought to be generated by gravity waves caused by flow over terrain and amplifying with height. Associated cooling rates often suffice to create the supersaturations required for homogeneous freezing.

Ström et al. (1997) deduced cooling rate standard deviations of $2-7 \mathrm{~K} \mathrm{~h}^{-1}$ from airborne measurements of vertical wind speeds in upper-tropospheric cirrus clouds over Central Europe. Kärcher and Ström (2003) corroborated these findings by analysing more recent aircraft vertical wind data taken at midlatitudes in the Northern and Southern Hemispheres. Similar properties of such fluctuations in the tropical upper troposphere were discussed by Jensen and Pfister (2004).
Properties of MTFs were measured in the lower stratosphere and examined in greater detail by Bacmeister et al. (1999). Distributions of temperature amplitudes at selected length-scales $\ell=1-12.8 \mathrm{~km}$ are shown to be Gaussian around the peak values, but exhibit wider tails caused by intermittent, large-amplitude waves tied to mountain lee waves or convection. As $\ell$ increases beyond $10 \mathrm{~km}$, the tails become less pronounced and Gaussians become better overall fits.

A strong support for the existence of background MTFs stems from the analysis of more than 4000 aircraft flight hours taken in the altitude range $7-22 \mathrm{~km}$ and at a variety of underlying topography, spanning the latitude range $70^{\circ} \mathrm{S}-80^{\circ} \mathrm{N}$, and covering all seasons (Gary, 2006). The universal properties and widespread existence of the background fluctuations is emphasised. Probability distribution functions of $T$ for Northern Hemisphere measurements are presented that closely match Gaussians. Average temperature amplitudes are close to $1 \mathrm{~K}$ associated with mean altitude displacements of air parcels of $\sim 100 \mathrm{~m}$ as inferred from the Microwave Temperature Profiler. The distributions also exhibit systematic dependences on season, altitude, latitude, and topography, whereby the latter factor explains most of the geographical variations. The temperature amplitudes are weaker over ocean than over land.

Background MTFs obtained from in situ measurements in the upper troposphere over the continental USA were analysed by Hoyle et al. (2005) in more detail. The MTF energy content decreases monotonically with decreasing $\ell$ in the absence of direct convective or lee wave influence. The distribution of MTF amplitudes peaks in the range $0.5-1 \mathrm{~K}(\ell=10-100 \mathrm{~km})$, falls off rapidly outside this range, and is skewed towards high values.

Figure 2(a) depicts an example of an MTF time series $T(t)$ around the mean value $T_{0}=225 \mathrm{~K}$ with a standard deviation of temperature amplitudes $\delta T=1 \mathrm{~K}$. The series has been generated synthetically based on

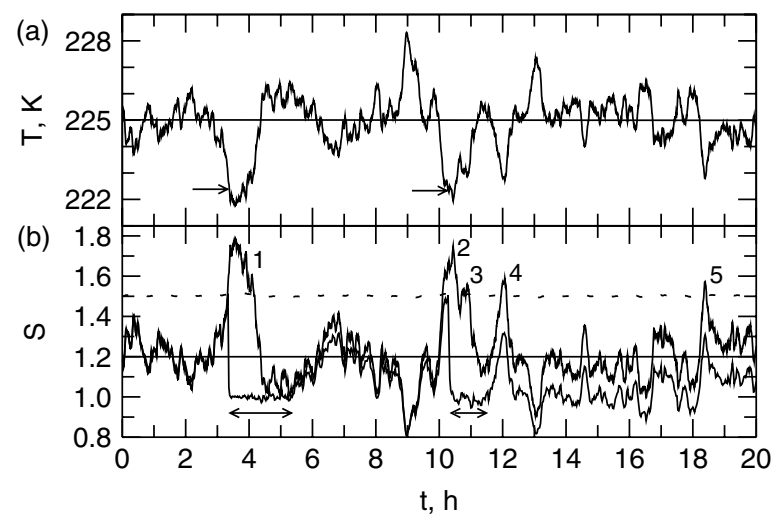

Figure 2. Time series of (a) background mesoscale temperature, $T$, fluctuations with a standard deviation $\delta T=1 \mathrm{~K}$, and (b) resulting fluctuations of ice saturation ratio $S$ (thick curves). Solid horizontal lines mark the base state at $T_{0}=225 \mathrm{~K}$ and $S_{0}=1.2$. The numbers close to the thick curve in (b) count potential ice formation events. The thin curve in (b) includes homogeneous freezing, growth, and sedimentation from numerical simulations and the dotted curve shows the actual freezing thresholds. Arrows mark (a) onset and (b) duration of cirrus events. 
measured power spectra and therefore exhibits the same statistical properties as the original data (Hoyle et al., 2005). Occasionally, quite strong deviations from the mean $T$ at $t \approx 9 \mathrm{~h}$ and at $t \approx 3.5 \mathrm{~h}$ and $10.5 \mathrm{~h}$ are found. The associated temperature PDF is well approximated by a constrained normal distribution,

$$
\frac{\mathrm{d} P_{T}}{\mathrm{~d} T}=\frac{1}{\mathcal{N}_{T}} \frac{1}{\sigma_{T}} \frac{1}{\sqrt{2 \pi}} \exp \left\{-\frac{\left(T-T_{0}\right)^{2}}{2 \sigma_{T}^{2}}\right\}, \quad \sigma_{T}=\delta T,
$$

where $\mathrm{d} P_{T} / \mathrm{d} T=0$ outside of $T_{0} \pm 3 \delta T$ and $\mathcal{N}_{T}$ is a normalisation factor accounting for the finite limits over which Equation (2) is defined.

In Figure 3(a) we show that Gaussians are indeed excellent approximations to the mesoscale distribution of $T$ in background conditions. We plot Equation (2) for different choices of $\delta T$ that were found in the observational data (solid curves) along with numerical distributions obtained directly from the time series (stepped lines). The numerical PDFs become statistically uncertain outside these ranges, justifying the restriction of $T$ in Equation (2) to values within the $3 \sigma_{T}$ limits. (Results are similar for other $\delta T$ values.)

Figure 2(b) shows the fluctuations of $S$ (thick curve) that are driven by the $T$ variations given in Figure 2(a). The time series $S(t)$ and the mean value $S_{0} \equiv S\left(T_{0}\right)=$ 1.2 were calculated using the saturation vapour pressure $p_{\text {sat }}$ over pure hexagonal ice (Murphy and Koop, 2005),

$$
\begin{aligned}
p_{\text {sat }}(T) & =\vartheta \exp \left(\frac{-\theta}{T}\right), \\
S(T) & =\frac{p_{\mathrm{v}}}{p_{\text {sat }}}=\alpha \exp \left(\frac{\theta}{T}\right), \quad \alpha=\frac{p_{\mathrm{v}}}{\vartheta},
\end{aligned}
$$

where $\vartheta=3.4452 \times 10^{10} \mathrm{hPa}, \theta=6132.9 \mathrm{~K}$, and $p_{\mathrm{v}}$ is the $\mathrm{H}_{2} \mathrm{O}$ partial pressure. We have chosen this expression for $p_{\text {sat }}$ because of its numerical simplicity and high accuracy in cirrus conditions. Equation (3b) neglects adiabatic changes of $p_{\mathrm{v}}$ and fluctuations of $p_{\mathrm{v}}$ that are not correlated with $T$, as discussed in Appendix B.

Cooling and warming events translate into respective clear-sky super- and subsaturations (thick curves in Figures 2(a) and (b)). On average, the $T$ fluctuations are symmetrically distributed around $T_{0}$, but the excursions in $S$ around $S_{0}$ are asymmetric owing to the exponential dependence of $S$ on $T$. Using Equation (3b), we define with $j=1,2,3, \ldots$ and $T_{j \mp}=T_{0} \mp j \delta T$,

$$
\begin{gathered}
S_{j \pm}=\alpha \exp \left(\frac{\theta}{T_{j \mp}}\right) \simeq S_{0} \exp \left(\frac{ \pm j \delta T \theta}{T_{0}^{2}}\right), \\
\Sigma_{j}=S_{j+}-S_{j-} \simeq 2 S_{0} \sinh \left(\frac{j \delta T \theta}{T_{0}^{2}}\right) .
\end{gathered}
$$

The approximations in Equations 4(a) and (b) are acceptable for $j \leq 3$ (within three standard deviations of the mean of $T$ ). In Figure 2(b), $S_{3+}-S_{0}=0.6$ but $S_{3-}-S_{0}=0.4$ at $T_{0}=225 \mathrm{~K}$ and $S_{0}=1.2$. The $\Sigma_{j}$ are measures of the distribution variance; practically all $S$ values lie within $\Sigma_{3}$.

In five cases, $S(t)$ surpasses the homogeneous freezing thresholds $S_{\mathrm{cr}}$ from Equation (1) (dotted curve in Figure 2(b)). These are potential ice formation events. However, ice particles will not always form. To illustrate this point, we added $S(t)$ from numerical parcel simulations of ice formation, growth, and sedimentation as a thin curve. The simulations have been driven by $T(t)$ from Figure 2(a) and initialised with $S_{0}=1.2$ at $p=225 \mathrm{hPa}$. Ice particles have been assumed to fall out of a $300 \mathrm{~m}$-thick layer according to their calculated terminal fall speeds to mimic loss of ice water from the nucleation region. In the simulations, ice forms only two times: at $t=3.3 \mathrm{~h}$ with $n=6 \mathrm{~cm}^{-3}$ and at $t=10.3 \mathrm{~h}$ with $n=1 \mathrm{~cm}^{-3}$, marked by arrows in Figure 2(a). The arrows in Figure 2(b) denote the time span where ice is present in the nucleation layer ( $2 \mathrm{~h}$ and $70 \mathrm{~min}$, respectively). (a)

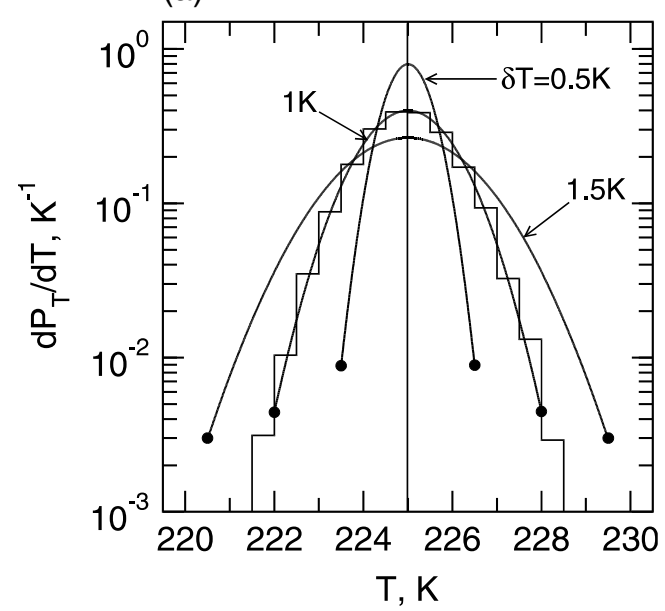

(b)



Figure 3. Probability distributions of (a) temperature $T$ and (b) ice saturation ratio $S$ derived from time series similar to those shown in Figure 2 for different standard deviations of temperature amplitudes $\delta T$. The solid curves are analytical approximations valid within the regions marked by filled circles, while the stepped lines are obtained numerically for $\delta T=1 \mathrm{~K}$. The assumed mean values $T_{0}$ and $S_{0}$ are indicated by vertical lines. 
We call attention to two effects that keep $S$ below $S_{\text {cr }}$, relative to the clear-sky saturation ratio history. Sedimentation removes a portion of the $\mathrm{H}_{2} \mathrm{O}$ from the layer that would otherwise be available for nucleation and growth in a subsequent cloud event. This explains why the thin curve lies below the thick curve in Figure 2(b) after the first cloud event, and why the third, fourth and fifth potential cloud events are not realised. We also see that, as $S_{0}$ decreases due to sedimentation losses, the $S$ amplitudes become smaller relative to the clear-sky case, in agreement with Equation 4(a). In a large-scale model, the loss of ice water might be compensated by transport of $\mathrm{H}_{2} \mathrm{O}$ into this region.

More importantly, once ice forms, the crystals rapidly remove $\mathrm{H}_{2} \mathrm{O}$ vapour in excess of saturation by diffusional growth. This causes the fluctuations of $S$ to be strongly damped within cirrus clouds formed by homogeneous freezing. The removal of supersaturation and associated damping of oscillations in $S$ are controlled by the instantaneous relaxation time-scale $\tau_{S}$,

$$
\tau_{S}=\frac{1}{4 \pi D n r \beta C \phi},
$$

where $D$ is the diffusion coefficient of $\mathrm{H}_{2} \mathrm{O}$ molecules in air, $C$ and $\phi$ are the ice crystal capacitance and ventilation factors, and $\beta$ accounts for gas kinetic corrections. For non-spherical ice crystals $(C \neq 1), r$ is interpreted as the radius of a volume-equivalent sphere. The function $\beta$ is defined in Equation (A.1). The choice $C=\phi=1$ has been made for convenience of discussion in this work and could easily be relaxed to include effects of non-spherical shapes on ice particle growth rates. We note that $\tau_{S}$ typically ranges between a few minutes and a few hours. The values $\tau_{S}$ immediately after freezing are displayed in Figure 1(b). Persistent in-cloud supersaturations are still possible, but extend only rarely beyond $\left(S_{1+}-S_{0}\right)$ in the mean. Long $\tau_{S}$ values (>30 min) may occur in regions with few particles as found in lower parts of the cloud and close to the cloud boundaries, and in very cold, thin ice clouds with small particles.

As fewer crystals form in the second event because of a lower cooling rate, the oscillations are larger than in the first cloud event (Figure 2(b)). The damping explains why the third potential cloud event is not realised. Ice formation in weak cooling events can be 'shadowed' (Hoyle et al., 2005).

We now link the ice nucleation process to the statistical properties of the MTFs. Once we know the dependence of the mean cooling rates $\bar{\omega}$, induced by the MTFs, on $\delta T$, we can estimate mean ice crystal number densities $\bar{n}$ for further use in section 3. In the case of the background MTFs from Hoyle et al. (2005), $\bar{\omega}$ can be approximated by (in practical units)

$$
\bar{\omega}\left[\mathrm{Kh}^{-1}\right]=8.2 \times \delta T[\mathrm{~K}] .
$$

It is possible that mesoscale gravity waves originating from specific sources such as lee waves or convection exhibit relationships that differ from Equation (6). We comment on this subject further in section 5 .
We computed the probability of occurrence of cooling rates from the background MTFs for different $\bar{\omega}$ and found

$$
\omega \frac{\mathrm{d} P_{\omega}}{\mathrm{d} \omega}=\frac{2}{c_{0}}\left(\frac{\omega}{\omega_{0}}\right) \exp \left\{-\left(\frac{\omega}{\omega_{0}}\right)^{2}\right\}, \quad \omega_{0}=c_{0} \bar{\omega},
$$

with $c_{0}=1.6$ and the mean cooling rate $\bar{\omega}$ from Equation (6). Using the approximate scaling $n \propto \omega^{3 / 2}$ as motivated in section 2.1, the mean total ice crystal concentration $n_{\text {tot }}$ resulting from homogeneous freezing follows from

$$
n_{\text {tot }}=\int_{0}^{\infty} n(\omega) \frac{\mathrm{d} P_{\omega}}{\mathrm{d} \omega} \mathrm{d} \omega=\frac{4}{5} \Gamma\left(\frac{5}{4}\right) \sqrt{c_{0}} n(\bar{\omega}) \simeq n(\bar{\omega}),
$$

where

$$
\Gamma(\mu+1)=\int_{0}^{\infty} x^{\mu} \exp (-x) \mathrm{d} x
$$

is the Gamma function. However, the actual $n_{\text {tot }}$ will be larger. Deriving a statistic of $n_{\text {tot }}$ over many freezing events for use in the cloud scheme must consider that shadowing is more effective at high cooling rates, because the resulting high ice crystal concentrations more effectively suppress subsequent supersaturation (Figure 2(b)). Furthermore, most of the small cooling rates do not contribute to freezing on average. Therefore, large $\omega$ values should be given higher weight than obtained by just averaging over the cooling rate distribution as in Equation (8). Hoyle et al. (2005) report a factor of 2 increase in $n_{\text {tot }}$ inferred from numerical modelling compared to simple averaging, which we confirm with our own numerical simulations. Instead of Equation (8), we therefore use the approximate relation

$$
n_{\text {tot }} \simeq 2 n(\bar{\omega}) \simeq n\left(c_{1} \bar{\omega}\right), \quad c_{1}=2^{2 / 3},
$$

along with Equation (A.3) to determine the mean ice crystal number densities. Hence, Equation (6) provides the link between ice formation and the statistical properties of the MTFs. According to Figure 1(a), a $T$ series with $\delta T=$ $1 \mathrm{~K}$ leading to $\bar{\omega} \approx 8.2 \mathrm{~K} \mathrm{~h}^{-1}$ would cause the production of $0.6 \mathrm{~cm}^{-3}$ crystals at $220 \mathrm{~K}$, if Equation (8) were used. The correct concentration from Equation (9) is given by $1.2 \mathrm{~cm}^{-3}$, read off Figure 1(a) at $c_{1} \bar{\omega} \approx 13 \mathrm{Kh}^{-1}$. These initial ice crystal number densities are in good agreement with in situ data taken in non-convective cirrus, as noted in section 2.1.

In summary, we demonstrate that temperatures and cooling rates originating from background mesoscale dynamical variability follow simple statistical distribution laws. We assume that these laws remain approximately valid for cooling rates generated by orographic or convective forcing. Knowing the standard deviation of the temperature amplitudes allows us to fix the PDFs of temperature and cooling rates, to study clear-sky relative humidity fluctuations, and to estimate the mean concentration and size of ice crystals formed by homogeneous freezing consistent with in situ observations and laboratory studies. 


\subsection{Clear-sky humidity distributions}

We showed that the Gaussian temperature PDFs from Equation (2) transform with the help of Equation 3(b) into the following PDFs of the clear-sky ice saturation ratios (Kärcher and Haag, 2004):

$$
\begin{aligned}
\frac{\mathrm{d} P_{S}}{\mathrm{~d} S}= & \frac{1}{\mathcal{N}_{S}} \frac{1}{\sigma_{S} \sqrt{2 \pi}} \frac{1}{S \ln ^{2}(S / \alpha)} \\
& \times \exp \left[-\beta_{S}\left\{\frac{1}{\ln (S / \alpha)}-\frac{1}{\ln \left(S_{0} / \alpha\right)}\right\}^{2}\right], \\
\mathcal{N}_{S}= & \frac{1}{2}\left(\operatorname{erf}\left[\sqrt{\beta_{S}}\left\{\frac{1}{\ln \left(S_{0} / \alpha\right)}-\frac{1}{\ln \left(S_{3+} / \alpha\right)}\right\}\right]\right. \\
& \left.-\operatorname{erf}\left[\sqrt{\beta_{S}}\left\{\frac{1}{\ln \left(S_{0} / \alpha\right)}-\frac{1}{\ln \left(S_{3-} / \alpha\right)}\right\}\right]\right)
\end{aligned}
$$

In Equations (10), $\beta_{S}=1 /\left(2 \sigma_{S}^{2}\right), \sigma_{S}=\delta T / \theta, \mathcal{N}_{S}$ is the normalisation factor, and

$$
\operatorname{erf}(x)=(2 / \sqrt{\pi}) \int_{0}^{x} \exp \left(-t^{2}\right) \mathrm{d} t
$$

denotes the error function for which computationally efficient yet accurate analytical approximations are available (Abramowitz and Stegun, 1972, p.299, Equation 7.1.26). Examples are displayed in Figure 3(b) consistent with the three cases shown in Figure 3(a). The PDFs are skewed towards high $S$, because of the exponential dependence of $S$ on $1 / T$. The skewness increases with $S_{0}$ and $\delta T$. The full distribution widths $\Sigma_{j}$ follow from Equation 4(b); outside of the interval $\left[S_{3-}, S_{3+}\right]$, marked by filled circles in Figure 3(b), $\mathrm{d} P_{S} / \mathrm{d} S=0$. Note that Equation (10) approaches a $\delta$ distribution as $\delta T \rightarrow 0$.

We have emphasised that mesoscale variability in cooling rates is the controlling factor for ice initiation in cirrus. This temperature variability is connected with a PDF of $S$. This PDF of $S$ will be used later to derive cloud fraction changes consistent with microphysical changes derived from the cooling rate PDF.

Figure 4 shows the PDF (stepped line) of clear-sky ice saturation ratio $S$ obtained from airborne measurements during the Interhemispheric Differences in Cirrus Properties From Anthropogenic Emissions (INCA) campaign in Punta Arenas, Chile. Water vapour mass mixing ratios were measured with a frost-point hygrometer (Ovarlez et al., 2002). The precision of these measurements is \pm 0.03 ( $1 \sigma$ limits) in terms of $S$. A Counterflow Virtual Impactor (CVI; Ström et al., 2003) was deployed to detect ice crystals with aerodynamic radii $>2-3 \mu \mathrm{m}$ down to low concentrations of $\sim 0.3$ crystals per litre of air. We have used the CVI data to discriminate between cloudy and cloud-free data points. We have computed $S$ with the help of ice saturation mass mixing ratios given by

$$
q_{\mathrm{sat}}(T)=\epsilon \frac{p_{\mathrm{sat}}}{p}
$$

where $\epsilon=0.622$ is the ratio of molecular masses of water and air molecules and $p_{\text {sat }}$ is taken from Equation 3(a), using the measured temperatures. The clear-sky PDFs comprise all data points for which the CVI signalled no significant ice crystal concentrations.

The observations exhibit multiple humidity modes, representative for different (partly stratospheric) air masses probed during individual flights (Kärcher and Haag, 2004). A dry mode is centred around $S=0.8$, and other dry modes exist at even lower values. Here, we focus on the supersaturated mode. The data points comprising this mode were taken in cloud-free air outside of but close to cirrus, including upper cloud layers where most of the ice crystals formed. The dataset represents several hours of measurements in relatively similar meteorological conditions and with similar dynamical forcings, i.e. mostly frontal layer clouds and only few cases with clear orographic forcing or jet stream influence (Gayet et al., 2006). In the relatively unpolluted regions over

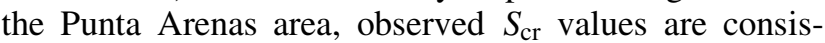
tent with a range of homogeneous freezing thresholds $\left(S_{\mathrm{cr}}=1.5-1.6\right)$.

We have used the campaign-average temperature $(225 \mathrm{~K})$, pressure $(270 \mathrm{hPa})$, ice saturation ratio $\left(S_{0}=1.15\right)$ (Ovarlez et al., 2002), and temperature fluctuations $(\delta T=1 \mathrm{~K})$ (Kärcher and Ström, 2003) to calculate the distribution parameters in Equation (10) and to approximate the moist mode in Figure 4. Slight variations of the observed $S_{0}$ and $\delta T$ within the data uncertainty result in very similar distributions. The value $\delta T=1 \mathrm{~K}$ is close to that inferred from the mean vertical wind speed of $26 \mathrm{~cm} \mathrm{~s}^{-1}$ (equivalent adiabatic cooling rate of $9 \mathrm{~K} \mathrm{~h}^{-1}$ ) measured in updraught regions. Finally, $\mathrm{d} P_{S} / \mathrm{d} S$ has been scaled in absolute terms to compare with the observations, and the analytical PDF is shown as a solid curve in Figure 4.

The skewed shape of $\mathrm{d} P_{S} / \mathrm{d} S$ as given by Equation (10) is supported by these in situ measurements, assuming that the width of $\mathrm{d} P_{S} / \mathrm{d} S$ is mainly connected with temperature variability. The fact that the distribution shown in Figure 4 show a higher probability for large $S$

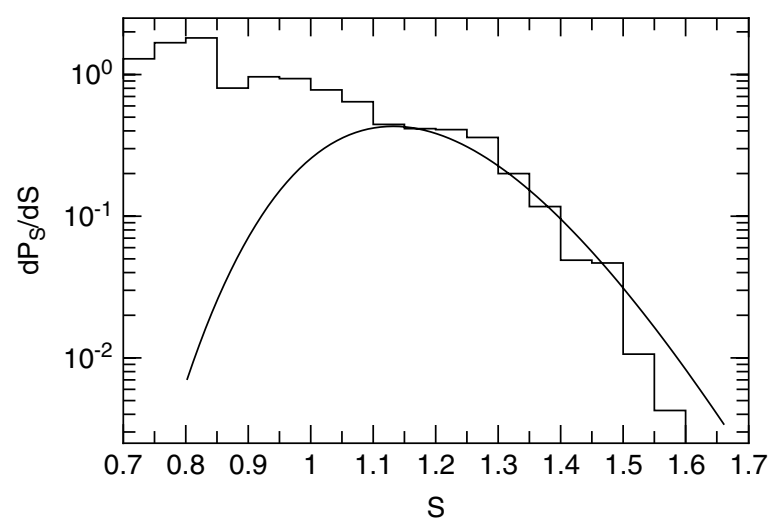

Figure 4. Distribution of clear-sky ice saturation ratio $S$ taken from in situ measurements (stepped line) over Punta Arenas, Chile. The measurements represent averages over the probed temperature range below $235 \mathrm{~K}$; most of the data were taken in the range $225 \pm 5 \mathrm{~K}$ in moist air masses outside of but close to cirrus clouds. The solid curve is an analytical distribution for the supersaturated mode calculated with mean values $\delta T=1 \mathrm{~K}$ and $S_{0}=1.15$ taken from the observations. 
values than the data, is explained by the fact that data points above the freezing thresholds $S>S_{\mathrm{cr}}=1.5-1.6$ have been removed from the dataset, because they are counted as in-cloud data points.

To link the clear-sky PDF of $S$ to the cloud fraction in section 3 , we need to determine the portion of the distribution that is located above the homogeneous freezing threshold $S_{\text {cr }}$ from Equation (1). Once $\mathrm{d} P_{S} / \mathrm{d} S$ extends above this threshold, ice crystals will form. The fraction of $\mathrm{d} P_{S} / \mathrm{d} S$ above $S_{\mathrm{cr}}$ is given by

$$
\begin{aligned}
& f\left(S>S_{\mathrm{cr}}\right)=\int_{S_{\mathrm{cr}}}^{S_{3}+} \frac{\mathrm{d} P_{S}}{\mathrm{~d} S} \mathrm{~d} S \\
&=\frac{1}{2 \mathcal{N}_{S}}\left(\operatorname{erf}\left[\sqrt{\beta_{S}}\left\{\frac{1}{\ln \left(S_{0} / \alpha\right)}-\frac{1}{\ln \left(S_{3+} / \alpha\right)}\right\}\right]\right. \\
&\left.\quad-\operatorname{erf}\left[\sqrt{\beta_{S}}\left\{\frac{1}{\ln \left(S_{0} / \alpha\right)}-\frac{1}{\ln \left(S_{c r} / \alpha\right)}\right\}\right]\right) .
\end{aligned}
$$

If $S_{\mathrm{cr}}>S_{3+}, f=0$ and if $S_{3-}>S_{\mathrm{cr}}, f=1$. In Equation (12), $S_{\mathrm{cr}}$ is taken at the temperature $T_{\mathrm{cr}}$ which follows from Equations (1) and (3b) by iteration. To avoid iteration, evaluating $S_{\mathrm{cr}}$ at $T_{0}$ is a very good approximation for $S_{0}>1$.

Figure 5 displays $f$ for different choices of the mean ice saturation ratio $S_{0}$ at $T_{0}=225 \mathrm{~K}$ as a function of $\delta T$ (solid curves). The initial steep increase in $f$ with rising $\delta T$ at fixed $S_{0}$ recalls the threshold behaviour of homogeneous freezing. The steepness increases as $\delta T$, and hence the distribution width, becomes smaller. The dotted curves were obtained for $T_{0}=205 \mathrm{~K}$, and reveal a stronger dependence of $f$ on $T_{0}$ when $S_{0}$ is large. The dependence of $f$ on the upper integration limit $S_{3+}$ is small. According to Figure 5, subsaturated conditions require rather large fluctuations of $T(\delta T>1.5 \mathrm{~K})$ to push the PDF of $S$ significantly far above the freezing threshold $(f>0.01)$. Such large MTF amplitudes are not prevalent in background conditions, as noted in section 2.2. This issue will be addressed further in section 3.1 .

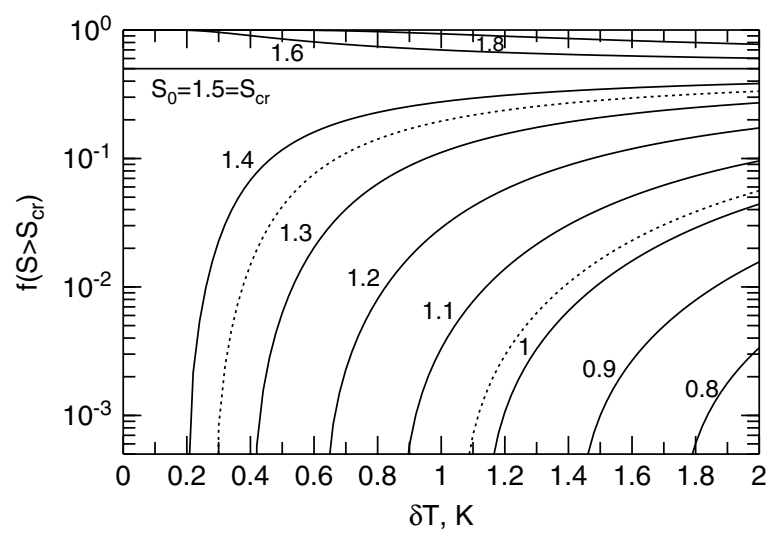

Figure 5. Fraction $f$ of the clear-sky distribution of ice saturation ratio $S$ extending above the homogeneous freezing threshold $S_{\mathrm{cr}}$ as a function of standard deviations $\delta T$ of mesoscale fluctuation temperature amplitudes. The labels denote assumed clear-sky mean values $S_{0}$, the horizontal line coinciding with $S_{\mathrm{cr}}$. All solid curves are evaluated at $T_{0}=225 \mathrm{~K}\left(S_{\mathrm{cr}}=1.5\right)$. The dotted curves are for $S_{0}=1$ and 1.4 taken at $205 \mathrm{~K}\left(S_{\mathrm{cr}}=1.59\right)$.
In summary, important features of clear-sky PDFs of $S$ controlling in situ ice formation and growth are caused by mesoscale temperature variability. The distribution variance is expressed uniquely in terms of the mean values $T_{0}$ and $S_{0}$ and the standard deviation $\delta T$ of the MTF. The consistency between observed and modelled total ice crystal number densities, clear-sky PDFs of $S$, and mean cooling rates, all following from $\delta T$, is emphasised.

\subsection{In-cloud humidity distributions}

Next, we define the PDF $\mathrm{d} P_{q}^{\mathrm{c}} / \mathrm{d} q$ of total water mass mixing ratio $q$ inside cirrus. Here, $q$ is defined as the sum of the water vapour mass mixing ratio $q_{\mathrm{v}}^{\mathrm{c}}$ inside cloud and the local cloud ice mass mixing ratio. We further define the in-cloud ice saturation ratio $S_{0}^{\mathrm{c}}=q_{\mathrm{v}}^{\mathrm{c}} / q_{\mathrm{sat}}$. Because air containing cirrus ice crystals can be subor supersaturated, and supersaturated air not necessarily contains ice, the partitioning of $\mathrm{H}_{2} \mathrm{O}$ between gas and particle phase at a given $q$ value is ambiguous. Instead, both the PDFs of vapour inside cloud and cloud ice must be known in order to properly define the cloud fraction changes.

The distribution of ice mass is the most important property for determining microphysical process rates and the radiative properties of cirrus layers ( $\mathrm{Fu}$ et al., 2000; Carlin et al., 2002; Gu and Liou, 2006). Observed distributions of relative humidities inside cirrus show mean values above but close to ice saturation (Jensen et al., 2001; Ovarlez et al., 2002; Haag et al., 2003). Notable exceptions may occur in thin tropical cirrus at low (<200 K) temperatures (Peter et al., 2006), but the causes are currently not well understood.

Because $\mathrm{H}_{2} \mathrm{O}$ vapour is of secondary relevance for the radiative effects of cirrus relative to the effect of cloud ice, a very detailed representation of the variability of vapour inside cloud is not necessary. We therefore express $\mathrm{d} P_{q}^{\mathrm{c}} / \mathrm{d} q$ as being composed of homogeneously distributed vapour PDF in the form of a delta function, $\delta\left(q-q_{\mathrm{v}}^{\mathrm{c}}\right)$, and a PDF of cloud ice as discussed below that accounts for the horizontal variability of the ice phase. As in the clear-sky case, we use in situ data to constrain the shape of the small-scale distribution of cloud ice.

Recalling our discussion of $\tau_{S}$ from section 2.3, assuming equilibrium for in-cloud water vapour is not always appropriate for cirrus. This is further detailed in section 4. Therefore, we allow non-equilibrium vapour states in the presence of cloud ice, so $q_{\mathrm{v}}^{\mathrm{c}}$ may deviate from $q_{\text {sat }}$. In this way, ice crystals form in supersaturated air and then may deplete the supersaturation by diffusional growth. Ice crystals can exist in subsaturated conditions, because sublimation is not rapid at low temperatures. Such cases can be brought about by sedimentation of large crystals into subsaturated cloud layers. Both growth and evaporation tend to restore saturation. This captures the main effect of water vapour in cirrus.

Figure 6 shows two PDFs of the cirrus ice water content $m$ obtained from the INCA measurements (stepped 


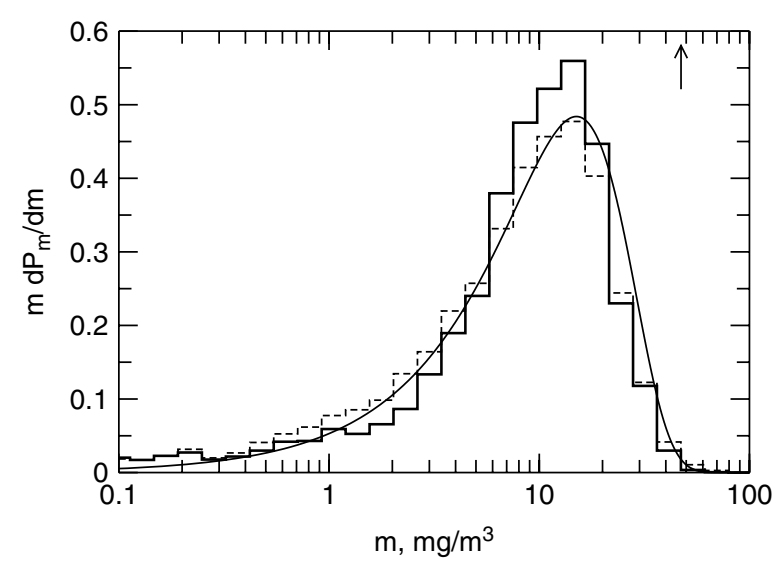

Figure 6. Distribution of cirrus cloud ice water content $m$ taken from in situ measurements (stepped lines) over Punta Arenas, Chile. Measurements represent averages over $\pm 5 \mathrm{~K}$ (solid) and $\pm 2 \mathrm{~K}$ (dashed) around the mean temperature $(225 \mathrm{~K})$. There was no significan influence of convection during these measurements. The solid curve is an analytical distribution constrained by the observed total ice wate content of $\sim 12 \mathrm{mg} \mathrm{m}^{-3}$ of air. The mean water vapour mass at ice saturation is $\sim 48 \mathrm{mg} \mathrm{m}^{-3}$ of air (arrow).

lines), as introduced in section 2.3. To derive these distributions, we have used the Forward Scattering Spectrometer Probe (FSSP-300) and 2D-C cloud probe data with $1 \mathrm{~s}$ time resolution. Together, these cloud probes cover the ice crystal size range 3-800 $\mu \mathrm{m}$; details of their characteristics are summarised by Ström et al. (2003) and Gayet et al. (2006). For the solid stepped line, we have used measurements for which $T$ lay within $\pm 5 \mathrm{~K}$ around the mean temperature $225 \mathrm{~K}$, in which most of the data were taken. To show the robustness of the results, we plot the same data selected within a $\pm 2 \mathrm{~K}$ interval (dashed stepped line).

We represent the observations from Figure 6 fairly well with (solid curve),

$$
m \frac{\mathrm{d} P_{m}}{\mathrm{~d} m}=\frac{2}{\sqrt{\pi}}\left(\frac{m}{m_{0}}\right) \exp \left\{-\left(\frac{m}{m_{0}}\right)^{2}\right\}, \quad m_{0}=\sqrt{\pi} \bar{m},
$$

where $\bar{m}$ is the observed mean ice water content. We point out that the single parameter $m_{0}$ also determines the variance of this unimodal PDF. Its specific form is brought about by a combination of large-scale advective moisture transport, growth, and sedimentation of ice crystals all affecting $m_{0}$.

Distributions of $m$ from airborne measurements such as shown in Figure 6 are rare in the literature, calling for more observational studies. The few examples include the works of Wood and Field (2000) and Field et al. (2005) for midlatitude and Heymsfield and McFarquhar (1996) for tropical cirrus. Along with the INCA data, these studies suggest that Equation (13) provides a simple predictive tool for different types of non-convective cirrus. It is typically found that the cloud ice constitutes only a minor fraction of total water content in stratiform cirrus. In case of INCA, this fraction is about $20 \%$ on average.
In summary, important features of in-cloud PDFs of total water controlling stratiform cirrus growth and decay are described by combining a $\delta$ distribution for water vapour that allows deviations from saturation and a simple analytical function describing the subgrid variability of cloud ice. The distribution moments are determined by the gas and ice phase water content. In the cloud scheme presented in section 3.2, the two latter quantities are prognostic variables.

\section{Cloud scheme}

This section aims at deriving the basic equations governing our cirrus cloud scheme. While the water vapour mass mixing ratio in the cloud environment $q_{\mathrm{v}}^{\mathrm{e}}$ is diagnosed, the concentration inside cloud $q_{\mathrm{v}}^{\mathrm{c}}$, the cloud fraction $a$ and the grid mean water vapour and ice mass mixing ratios $q_{\mathrm{v}}$ and $q_{\mathrm{i}}$ as well as the grid-mean ice crystal number mixing ratio $c_{\mathrm{i}}$ serve as predicted variables. Figure 7 delineates the dependencies between these variables and the parameters $\delta T$ and $S_{\mathrm{cr}}$ controlling ice nucleation and growth. The total nucleated ice crystal number density $n_{\text {tot }}$ follows from the homogeneous freezing parametrization. Equations describing cloud formation and decay are presented in section 3.1 and 3.2, respectively. The source terms in these equations are consistently derived based on the PDFs from section 2 for each of the prognostic variables and include nucleation and depositional growth of ice crystals (formation) and sublimation of ice (decay).

\subsection{Cloud formation}

We first discuss the schematic presented in Figure 8. Figure 8(a) depicts the clear-sky PDF $\mathrm{d} P_{S} / \mathrm{d} S$ with the large- $S$ tail extending beyond the threshold $S_{\text {cr }}$ (dotted line). This clear-sky state could have been caused by cooling, by enhanced $\delta T$, and/or by transport of moisture. This PDF is difficult to observe in the atmosphere,

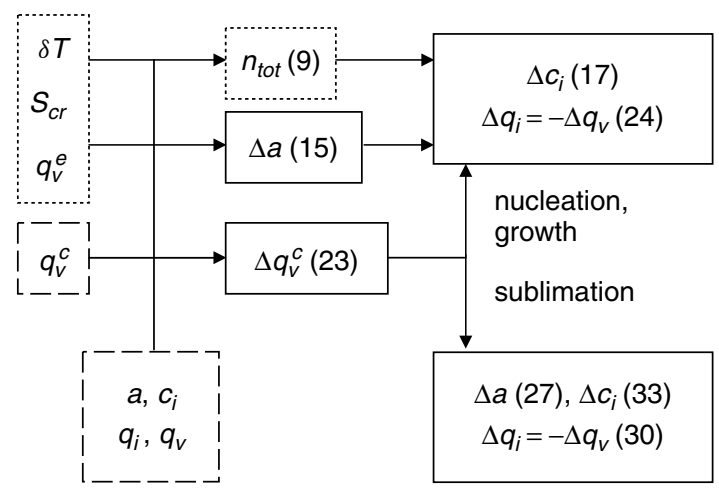

Figure 7. Schematic overview of connections between variables of the cirrus cloud scheme. Dashed (dotted) boxes indicate predicted (diagnosed) variables, solid boxes denote final predicted tendencies. Depending on whether the in-cloud supersaturation is positive or negative, the scheme increases cloud ice mass by depositional growth and possibly creates new cloud by nucleation or removes existing cloud by sublimation. Numbers in brackets denote equation numbers. 
(a)

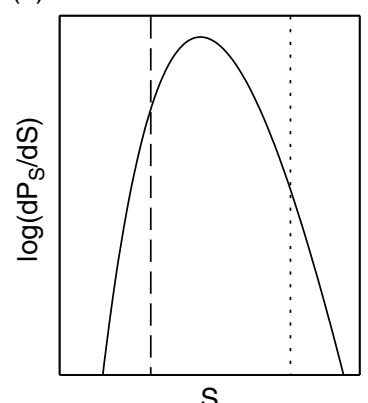

(b)

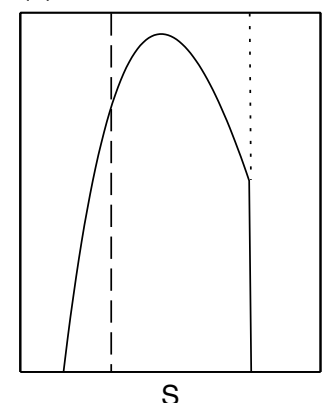

Figure 8. Evolution of the clear-sky distribution of ice saturation ratio after a homogeneous freezing event $((\mathrm{a}) \rightarrow(\mathrm{b}))$. Dashed lines mark ice saturation, and dotted lines mark the freezing threshold.

because of the very short homogeneous freezing timescales $\tau_{\mathrm{f}}$ of a few seconds at typical mesoscale cooling rates (Figure 1(b)).

Starting with Figure 8(a), as a result of aerosol particle freezing, ice crystals form and the portion of the distribution above $S_{\text {cr }}$ is removed from the clearsky PDF, as depicted in Figure 8(b). This defines the increase in fractional cirrus cover, as quantified below, and is supported by in situ measurements, as discussed in section 2.3. Within a global model time step, there might be time available for diffusional growth of the new crystals, affecting the grid-mean humidity and ice water content. The influence of nucleation and condensation processes on the variability of the clear-sky PDF is not considered.

We now relate the clear-sky PDF from Equation (10) to the fractional cirrus cloud cover $a$. This is accomplished by defining the auxiliary PDF

$$
\Psi_{a}(S)=(1-a) \frac{\mathrm{d} P_{S}}{\mathrm{~d} S} .
$$

Integrating Equation (14) in the limits $S_{3-}$ and $S_{3+}$ (see Equation (4a)) yields the total clear-sky fraction $(1-a)$.

Let us denote the cloud fraction from the previous time step by $a$ and let $f=0$. When proceeding to the next time step, the distribution may change such that $f>0$. The new cloud fraction is given by $a+\Delta a$. Applying Equation (14) in conjunction with Equations (10) and (12) yields the desired increase in cloud fraction

$$
\Delta a=\int_{S_{\mathrm{cr}}}^{S_{3+}} \Psi_{a} \mathrm{~d} S=(1-a) f\left(S>S_{\mathrm{cr}}\right) .
$$

Next, we derive the source terms for $q_{\mathrm{v}}, q_{\mathrm{i}}$ and $c_{\mathrm{i}}$. Together with $q_{\mathrm{v}}^{\mathrm{c}}$, these variables are to be predicted in a large-scale model and are affected by transport and other microphysical processes such as sedimentation and precipitation which are not addressed here. As noted in section 2.4 , the prognostic treatment of $q_{\mathrm{v}}^{\mathrm{c}}$ allows incloud supersaturation to be explicitly tracked, avoiding the necessity to apply saturation adjustment in cloudy air.
The clear-sky water vapour mass mixing ratio $q_{\mathrm{v}}^{\mathrm{e}}$ (in the cloud environment) is diagnosed from the relationship defining $q_{\mathrm{v}}$,

$$
q_{\mathrm{v}}=(1-a) q_{\mathrm{v}}^{\mathrm{e}}+a q_{\mathrm{v}}^{\mathrm{c}} .
$$

The clear-sky ice saturation ratios needed to evaluate Equation (15) are given by $S_{0}=q_{\mathrm{v}}^{\mathrm{e}} / q_{\mathrm{sat}}$. (We do not use $S_{0}^{\mathrm{e}}$ to be consistent with the notation from section 2 .) With the grid-mean ice saturation ratio $S=q_{\mathrm{v}} / q_{\text {sat }}$, the above relation transforms into

$$
S_{0}=\frac{S-a S_{0}^{\mathrm{c}}}{1-a}, \quad a<1 .
$$

We discuss the instantaneous cloud fraction $a=f\left(S>S_{\mathrm{cr}}\right)$ with the help of Figure 9, where we show $a\left(S_{0}\right), a(S)$, and $S\left(S_{0}\right)$. To compute $S$ from $S_{0}$, we have assumed saturated conditions inside the cloud, for simplicity $\left(S_{0}^{\mathrm{c}}=1\right)$. The solid (dashed) curves are based on $\delta T=0.5$ (1) $\mathrm{K}$, because the observed $\delta T$ values appear to be most prevalent in this range. Figure 5 suggests that $S_{0}$ must rise toward $S_{\mathrm{cr}}$ in order to induce values of $a$ near unity. The increase in $a\left(S_{0}\right)$ is steeper the smaller $\delta T$; compare solid versus dashed curves in Figure 9.

Two important issues emerge from Figure 9. First, homogeneous ice formation becomes significant at $S_{0}=1.1-1.3$ and maximum grid-mean ice saturation ratios are $S \simeq 1.3$. Supersaturations on various spatial scales are observed in in situ measurements (Heymsfield et al., 1998; Gierens et al., 1999; Jensen et al., 2001; Haag et al., 2003) and by satellites (Spichtinger et al., 2003; Gettelman et al., 2006). This increases confidence in the physical soundness of our approach.

Second, we show the diagnostic relationship $a(S)$ proposed by Sundqvist et al. (1989) that is frequently employed in climate models (dotted curve). It predicts an early onset of cloud formation in grid-mean subsaturated conditions (here $S=0.7$ ), and $a$ increases monotonically to unity which is attained at $S=1$. Models

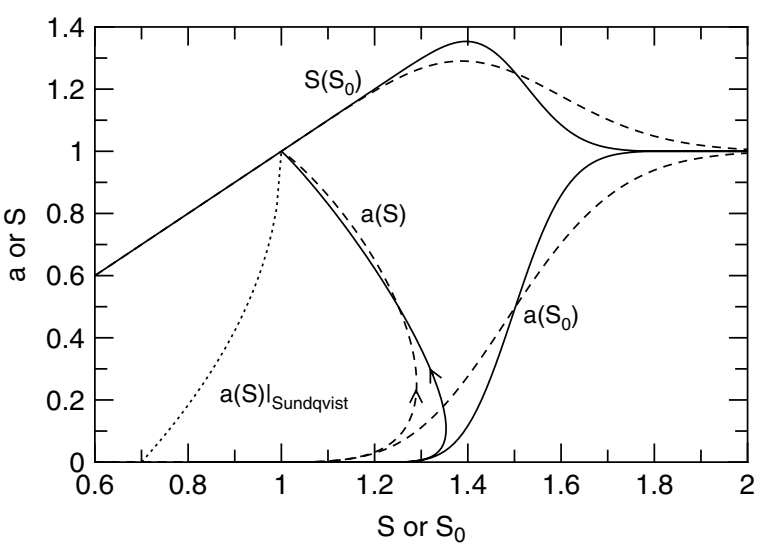

Figure 9. Instantaneous cirrus cloud fraction $a$ versus grid-mean, $S$, and clear-sky, $S_{0}$, ice saturation ratio, and $S\left(S_{0}\right)$ assuming saturation inside cloud (small $\tau_{S}$ ). Solid and dashed curves are computed for $\delta T=0.5 \mathrm{~K}$ and $1 \mathrm{~K}$, respectively. The curves assume $T_{0}=225 \mathrm{~K}$ where $S_{\mathrm{cr}}=1.48$. The diagnostic relationship $a(S)$ proposed by Sundqvist et al. (1989) is shown for comparison (dotted curve). 
employing diagnostic $a(S)$ relationships are not capable of predicting a supersaturated mean state without empirical assumptions. When inferred from our cloud scheme, $a(S)$ becomes multivalued and cannot simply be diagnosed. This occurs because supersaturation introduces a time history (arrows in Figure 9), requiring the prognostic treatment of $a$. A similar argument holds for cloud decay, because cloud ice can exist in subsaturated conditions (section 2.2).

The increase in grid-mean ice crystal number mixing ratio follows from

$$
\Delta c_{\mathrm{i}}=\Delta a \frac{n_{\mathrm{tot}}}{n_{\mathrm{a}}},
$$

where $n_{\text {tot }}$ is the nucleated concentration from Equations (9) and (6) and $n_{\mathrm{a}}=p /\left(k_{\mathrm{B}} T\right)$ is the number concentration of air molecules, with the Boltzmann constant $k_{\mathrm{B}}$. These ice crystals grow within the average time $\Delta t=\tau / 2$ available after freezing ( $\tau$ is the GCM time step), leading to an initial mean ice crystal size $\bar{r}$ (Equation (A.5)). The factor $1 / 2$ accounts for the fact that it is not known at which point within $\tau$ nucleation occurs. This adds the following contribution to the grid-mean ice water mass mixing ratio,

$$
\left(\Delta q_{\mathrm{i}}\right)_{S \leq S_{\mathrm{cr}}}=\Delta a q_{\mathrm{tot}}, \quad q_{\mathrm{tot}}=\frac{4 \pi \rho_{\mathrm{i}} n_{\mathrm{tot}} \bar{r}^{3}}{3 \rho_{\mathrm{a}}} .
$$

Our nucleation parametrization ensures that $q_{\mathrm{tot}}$ cannot exceed $\left(q_{\mathrm{cr}}-q_{\mathrm{sat}}\right)$, the difference between $\mathrm{H}_{2} \mathrm{O}$ mass mixing ratios at $S_{\mathrm{cr}}$ and saturation. However, it does not deal with the excess water mass above $S_{\mathrm{cr}}$ associated with $f>0$. This contribution must be added separately if not already deposited on the nucleated ice particles and is then given by

$$
\begin{aligned}
\left(\Delta q_{\mathrm{i}}\right)_{S>S_{\mathrm{cr}}} & =q_{\mathrm{sat}} \int_{S_{\mathrm{cr}}}^{S_{3+}}\left(S-S_{\mathrm{cr}}\right) \Psi_{a} \mathrm{~d} S \\
& =\Delta a q_{\mathrm{sat}} g_{\star}\left(S>S_{\mathrm{cr}}\right), \\
g_{\star}\left(S>S_{\mathrm{cr}}\right) & =\frac{1}{f\left(S>S_{\mathrm{cr}}\right)} \int_{S_{\mathrm{cr}}}^{S_{3+}}\left(S-S_{\mathrm{cr}}\right) \frac{\mathrm{d} P_{S}}{\mathrm{~d} S} \mathrm{~d} S,
\end{aligned}
$$

in our PDF-based framework. The $g_{\star}$ integral cannot be obtained in closed form, but is easily evaluated by numerical integration using Simpson's rule.

Another contribution to $q_{\mathrm{i}}$ stems from water vapour deposition in the already cloudy area. In-cloud water vapour $q_{\mathrm{v}}^{\mathrm{c}}$ is transferred to ice crystals via gas phase diffusion,

$$
\left(\frac{\partial q_{\mathrm{v}}^{\mathrm{c}}}{\partial t}\right)_{\mathrm{dep}}=-4 \pi D \frac{c_{\mathrm{i}} n_{\mathrm{a}}}{a} r \beta C \phi\left(q_{\mathrm{v}}^{\mathrm{c}}-q_{\mathrm{sat}}\right)=-\frac{q_{\mathrm{v}}^{\mathrm{c}}-q_{\mathrm{sat}}}{\tau_{S}}
$$

where $\left(c_{\mathrm{i}} n_{\mathrm{a}} / a\right)$ denotes the in-cloud ice crystal number concentration and the mean ice crystal radius $r$ is taken from

$$
r=\left(\frac{3 \rho_{\mathrm{a}} q_{\mathrm{i}}}{4 \pi \rho_{\mathrm{i}} c_{\mathrm{i}}}\right)^{1 / 3},
$$

where $\rho_{\mathrm{a}}$ is the mass density of air and $\rho_{\mathrm{i}}$ is the bulk mass density of ice. The monodisperse approximation Equation (21) works well in the diffusional growth phase after nucleation, where $c_{\mathrm{i}}$ stays constant and ice crystal size distributions tend to be narrow, because small crystals grow faster than larger ones, see Equation (C.1). Integrating Equation (20) over a time step $\tau$ yields the change of $q_{\mathrm{y}}^{\mathrm{c}}$ due to deposition and the corresponding change in grid-mean ice mass mixing ratio,

$$
\begin{aligned}
\left(\Delta q_{\mathrm{v}}^{\mathrm{c}}\right)_{\mathrm{dep}} & =-\left(q_{\mathrm{v}}^{\mathrm{c}}-q_{\mathrm{sat}}\right)\left\{1-\exp \left(-\tau / \tau_{S}\right)\right\}, \\
\left(\Delta q_{\mathrm{i}}\right)_{\mathrm{dep}} & =-a\left(\Delta q_{\mathrm{v}}^{\mathrm{c}}\right)_{\mathrm{dep}} .
\end{aligned}
$$

The total change in $q_{\mathrm{v}}^{\mathrm{c}}$ consists of the vapour content after nucleation in the newly developed cloud area and the vapour change in the already cloudy area,

$$
\Delta q_{\mathrm{v}}^{\mathrm{c}}=\frac{a}{a+\Delta a}\left(\Delta q_{\mathrm{v}}^{\mathrm{c}}\right)_{\mathrm{dep}}+\frac{\Delta a}{a+\Delta a} q_{\mathrm{vtot}},
$$

where $q_{\text {vtot }}$ consists of two parts. The first part is calculated within the nucleation parametrization using Equation (20) with the deposition time-scale $\tau_{s}$ characteristic for the nucleated particles (Figure 1(b)). This determines $q_{\text {tot }}$ from Equation (18). The second part represents the vapour content above $S_{\mathrm{cr}}$ determined by the clear-sky PDF that may not have been deposited already. This corresponds to Equation (19).

To conserve total water, the change in the grid-mean water vapour mass mixing ratio follows from

$$
\begin{aligned}
\Delta q_{\mathrm{i}} & =-\Delta q_{\mathrm{v}}=\left(\Delta q_{\mathrm{i}}\right)_{S \leq S_{\mathrm{cr}}}+\left(\Delta q_{\mathrm{i}}\right)_{S>S_{\mathrm{cr}}}+\left(\Delta q_{\mathrm{i}}\right)_{\mathrm{dep}} \\
& =-a\left(\Delta q_{\mathrm{v}}^{\mathrm{c}}\right)_{\mathrm{dep}}+\Delta a\left\{q_{\mathrm{tot}}+q_{\mathrm{sat}} g_{\star}\left(S>S_{\mathrm{cr}}\right)\right\} .
\end{aligned}
$$

The first term describes water vapour deposition over the existing fractional area $a$ already covered by cirrus. The second term accounts for ice formation and growth in the new cloud area $\Delta a$. Equations (15), (17), (22), (23) and (24) constitute the final set of prognostic equations describing cloud formation by nucleation and depositional growth of ice crystals.

\subsection{Cloud decay}

The term cloud decay summarises the processes that lead to a reduction of cloud cover and ice water content. Specifically, we treat sublimation of ice crystals. Figure 10 displays the corresponding sequence of processes. Sublimation occurs when cloudy air becomes subsaturated due to warming or drying out, i.e. the mean in-cloud subsaturation $S_{0}^{\mathrm{c}}-1<0$ is the driving force for sublimation. This causes an increase in the water vapour content in cloudy air, as indicated by the sequence (a) $\rightarrow$ (b). This increase corresponds to the difference between the solid and dashed vertical lines and determines the reduction of cloud fraction. The smallest ice crystals experiencing the highest subsaturations will completely sublimate first. Because cloud-free air is produced during this process, the cloud fraction decreases, 
(a)

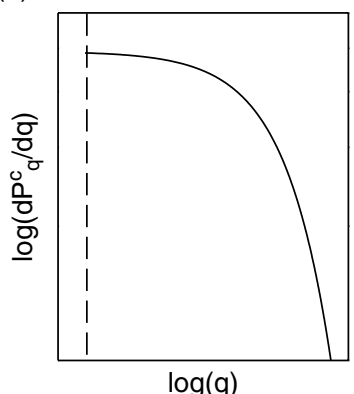

(b)

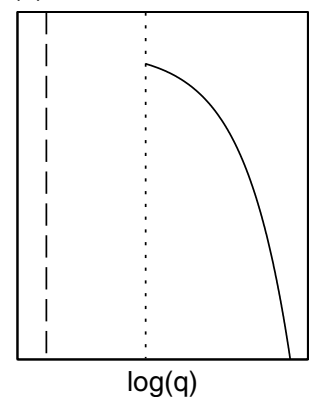

Figure 10. Evolution of the in-cloud distribution of total water after a change in water vapour during sublimation $((a) \rightarrow(b))$. The dashed and dotted lines mark the water vapour mass mixing ratio (represented

by a $\delta$ distribution) before and after sublimation, respectively.

some ice water is transferred into cloud-free air. Processes leading to a removal of cloud ice from the layer such as sedimentation of large crystals and conversion of pristine into precipitable ice would reduce the PDF variance.

According to our assumption of a homogeneous vapour PDF inside cloud and using Equation (13), we can write the PDF of total water mass mixing ratio inside cloud $q$ as,

$$
\frac{\mathrm{d} P_{q}^{\mathrm{c}}}{\mathrm{d} q}=\frac{2}{\sqrt{\pi}} \frac{1}{q_{0}} \exp \left\{-\left(\frac{q-q_{\mathrm{v}}^{\mathrm{c}}}{q_{0}}\right)^{2}\right\}, \quad q_{0}=\sqrt{\pi} \frac{q_{\mathrm{i}}}{a},
$$

where $\left(q_{\mathrm{i}} / a\right)$ denotes the simulated mean in-cloud ice mass mixing ratio and $q \geq q_{\mathrm{v}}^{\mathrm{c}}$. Equation (25) is shown in Figure 10(a) with the dashed line indicating the lowest in-cloud value $q=q_{\mathrm{v}}^{\mathrm{c}}$. During sublimation, the change in the mean $\mathrm{H}_{2} \mathrm{O}$ vapour mass mixing ratio is given by Equation (22a), $\Delta q_{\mathrm{v}}^{\mathrm{c}}=\left(\Delta q_{\mathrm{v}}^{\mathrm{c}}\right)_{\mathrm{dep}}$, which is always positive and equal to the difference between the vertical lines in Figure 10(b). With the auxiliary PDF

$$
\Psi_{a}^{\mathrm{c}}(q)=a \frac{\mathrm{d} P_{q}^{\mathrm{c}}}{\mathrm{d} q},
$$

the decrease in cirrus fraction over a time step is given by

$$
\Delta a=\int_{q_{\mathrm{v}}^{\mathrm{c}}}^{q_{\mathrm{v}}^{\mathrm{c}}+\Delta q_{\mathrm{v}}^{\mathrm{c}}} \Psi_{a}^{\mathrm{c}} \mathrm{d} q=-a \operatorname{erf}(-\xi), \quad \xi=\frac{\Delta q_{\mathrm{v}}^{\mathrm{c}}}{q_{0}} .
$$

The factor $\xi$ controls cirrus decay by sublimation and represents the ratio of the driving force $\Delta q_{\mathrm{v}}^{\mathrm{c}}$ and the local mean ice content $\left(q_{\mathrm{i}} / a\right)$ available for sublimation. It approaches zero for weak forcings $\xi \ll 1$, in which case $\Delta a$ vanishes linearly with $\Delta q_{\mathrm{v}}^{\mathrm{c}}$, i.e.

$$
\Delta a \rightarrow-a \cdot\left(\frac{2 \xi}{\sqrt{\pi}}\right) \rightarrow 0 .
$$

The opposite limit of $\xi \gg 1$ yields $\Delta a \rightarrow-a$ and is either obtained for strong forcings or low mean ice content.
The grid-mean ice mass mixing ratio is given by

$$
q_{\mathrm{i}}=\int_{q_{\mathrm{v}}^{\mathrm{c}}}^{\infty}\left(q-q_{\mathrm{v}}^{\mathrm{c}}\right) \Psi_{a}^{\mathrm{c}}(q) \mathrm{d} q .
$$

In conjunction with Equation (26), this relationship holds because of the assumption of a homogeneous in-cloud vapour PDF. After one time step, the change $\Delta q_{\mathrm{i}}$ then follows from

$$
q_{\mathrm{i}}+\Delta q_{\mathrm{i}}=\int_{q_{\mathrm{v}}^{\mathrm{c}}+\Delta q_{\mathrm{v}}^{\mathrm{c}}}^{\infty}\left\{q-\left(q_{\mathrm{v}}^{\mathrm{c}}+\Delta q_{\mathrm{v}}^{\mathrm{c}}\right)\right\} \Psi_{a}^{\mathrm{c}}(q) \mathrm{d} q .
$$

Subtracting Equation (28) from Equation (29) and performing the integration results in

$$
\Delta q_{\mathrm{i}}=-q_{\mathrm{i}}\left[1-\exp \left(-\xi^{2}\right)+\sqrt{\pi} \xi\{1-\operatorname{erf}(\xi)\}\right] .
$$

In the limit $\xi \ll 1$, we obtain

$$
\Delta q_{\mathrm{i}} \rightarrow-a \Delta q_{\mathrm{v}}^{\mathrm{c}}-\frac{\Delta a \Delta q_{\mathrm{v}}^{\mathrm{c}}}{2},
$$

for which we have used the asymptotic expansion $\operatorname{erf}(\xi) \rightarrow(2 \xi / \sqrt{\pi}) \exp \left(-\xi^{2}\right)$ along with Equation (27). The first term in Equation (31) accounts for ice evaporation over the total fractional cloud area $a$. The second term accounts for the fact that $a$ decreases during this process $(\Delta a<0)$. This limit is equivalent to assuming a uniform total water PDF. The opposite limit $\xi \gg 1$ with $\operatorname{erf}(\xi) \rightarrow 1$ yields $\Delta q_{\mathrm{i}} \rightarrow-q_{\mathrm{i}}$, as expected.

We do not explicitly consider MTF during cloud decay, because sublimation time-scales are usually much longer than nucleation time scales. Regardless, such oscillations implicitly contribute to the width of $\mathrm{d} P_{q}^{\mathrm{c}} / \mathrm{d} q$, as do fluctuations of $q$. Sedimentation losses or conversion to precipitable ice affect the in-cloud PDF via reductions in $q_{\mathrm{i}}$ and would lead to a narrowing of the PDF.

We plot the relative changes in $a$ and $q_{\mathrm{i}}$ from Equations (27) and (30) as a function of the parameter $\xi$ in Figure 11. Both curves depart linearly from zero for

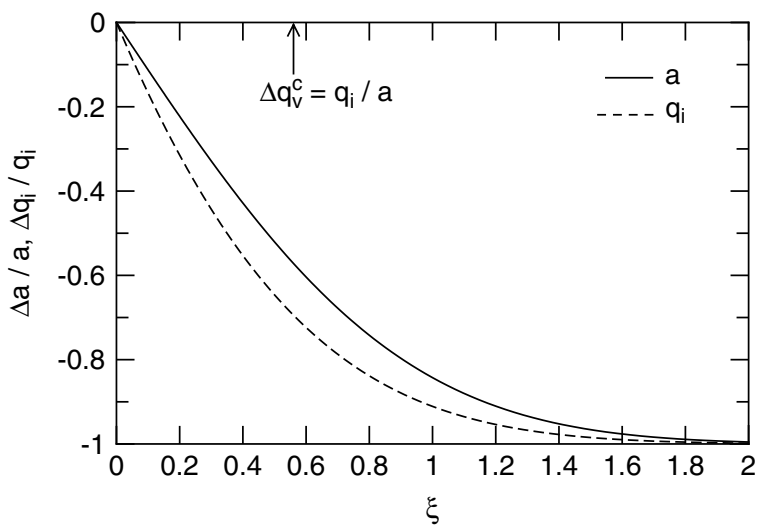

Figure 11. Relative changes of cirrus cloud fraction $a$ and gridmean ice mass mixing ratio $q_{\mathrm{i}}$ versus the dimensionless parameter $\xi$ controlling sublimation-driven cloud decay. The arrow indicates the value of $\xi=1 / \sqrt{\pi} \approx 0.56$ when the water vapour increase caused by the evaporating ice crystals equals the local mean ice content. 
small sublimation rates $(\xi<0.2)$ and approach the limit of full cloud dissipation for $\xi>1.8$. The changes become strongly nonlinear when the release of $\mathrm{H}_{2} \mathrm{O}$ vapour during ice evaporation is of the order of the local mean ice water content.

To complete our cloud scheme, we note the relations for the remaining variables $q_{\mathrm{v}}$ and $c_{\mathrm{i}}$. The change in gridmean water vapour mass mixing ratio follows directly from Equation (30),

$$
\Delta q_{\mathrm{v}}=-\Delta q_{\mathrm{i}}
$$

The decrease in the grid-mean ice crystal number mixing ratio is

$$
\Delta c_{\mathrm{i}}=-\left\{1-\mathcal{H}\left(\Delta q_{\mathrm{i}}+q_{\mathrm{i}}\right)\right\} c_{\mathrm{i}},
$$

with the Heavyside function defined by $\mathcal{H}(x)=1$ if $x>0$ and $\mathcal{H}(x)=0$ if $x \leq 0$. Consistent with the assumption of monodisperse ice crystals, $c_{\mathrm{i}}$ is kept constant until all cloud ice evaporates, in which case $c_{\mathrm{i}}$ is removed completely. In reality, $c_{\mathrm{i}}$ decreases during sublimation at a faster rate than ice mass due to a spread of ice particle sizes. In Appendix C, we estimate the impact of an assumed ice crystal size distribution on $\Delta c_{\mathrm{i}}$ and comment on possible uncertainties in section 4 . Together, Equations (27), (30), (32) and (33) describe cirrus decay by sublimation of ice crystals.

\section{Solutions}

In this section, we solve the equations for cloud fraction, condensate number and mass, and vapour content in a closed volume of air. We use a temporal resolution similar to a GCM. The only processes that are considered are cirrus nucleation, depositional growth and sublimation.

The forcing for cirrus formation (section 3.1) is achieved by prescribing a continuous large-scale uplift. To study the evolution of cirrus decay (section 3.2), we prescribe a constant downdraught speed to mimic largescale subsidence. Latent heat effects that counteract the imposed forcing are small for $T<235 \mathrm{~K}$ and are not accounted for. The change in temperature in one time step $\tau=30 \mathrm{~min}$ is given by $g w \tau / c_{p}$, with the vertical wind speed $w$, the acceleration of gravity $g$, and the specific heat capacity of air $c_{p}$. Air pressure, partial pressure, and number density changes follow accordingly from the adiabatic equation of state. The cloud scheme equations are integrated explicitly forward in time. We use constant mesoscale forcings $\delta T$ (cooling rates via Equation (6)), although in a global model, $\delta T$ and other parameters relevant to cloud forcing may vary, allowing our cloud scheme to respond more realistically to changes in local cloud-forcing conditions.

Figure 12 shows the time history of cirrus cloud formation by homogeneous freezing in typical midlatitude conditions $(\sim 250 \mathrm{hPa})$, starting at ice saturation at $230 \mathrm{~K}$ without cloud. The updraught speed is fixed to a value of
$1 \mathrm{~cm} \mathrm{~s}^{-1}$. The results in Figure 12(a) and (b) are based on a mesoscale forcing $\delta T=1 \mathrm{~K}$ for ice nucleation, while those in Figure 12(c) and (d) are obtained for a weaker forcing $\delta T=0.5 \mathrm{~K}$.

For strong forcing, the tails of the clear-sky PDFs are flatter than for weak forcing (Figure 3(b)), for which reason cirrus nucleation sets in earlier (compare arrows in Figure 12(b) and (d)), but proceeds at a slower pace, as displayed by the differences in $a$ between Figure 12(a) and (c). Both $S_{0}$ and $S$ reach higher peak values when the forcing is weak, consistent with Figure 9. (Here $S$ defines the grid mean saturation ratio.) To arrive at the same increase in cloud fraction at a given cooling rate, the peak $S_{0}$ value must be higher for a narrower distribution.

As $a$ increases towards unity, the mean clear-sky ice saturation ratio within the available fractional area $(1-a)$ must be pushed to increasingly higher values to trigger homogeneous freezing, because $\Delta a \propto(1-a)$. At some point, $S_{0}$ saturates. The cooling-induced rise in $S_{0}$ to increase $f$ is then balanced by an increased transfer of $\mathrm{H}_{2} \mathrm{O}$ vapour mass from the clear-sky to the in-cloud PDF during freezing via Equation (24), which acts to reduce $S_{0}$.

In overcast conditions, the strong (weak) forcing scenario creates $\sim 0.85(0.25) \mathrm{cm}^{-3}$ ice crystals and the corresponding mean number radii lie within $25-35 \mu \mathrm{m}$. Ice crystal number densities and radii will eventually change due to further dynamical and microphysical processes not considered in this solution. A direct comparison with observations is only meaningful when our cirrus scheme is applied in a GCM including these processes, and we refer to section 5.3 for further discussion. Because the saturation relaxation time after homogeneous freezing is short compared to the time step (Figure 1(b)), the incloud ice saturation ratio is always close to unity. For $a>0.8$, the ice water content (not shown) corresponds to $\sim 40$ (25) $\mathrm{mg} \mathrm{m}^{-3}$ in the case of strong (weak) forcing. These numbers are upper limits, because ice water losses are not accounted for in this calculation. Gayet et al. (2006) derive typical ice water contents in the range $3-20 \mathrm{mg} \mathrm{m}^{-3}$ for midlatitude cirrus at $220-230 \mathrm{~K}$.

Figure 13 shows the time history of cirrus decay, starting at $250 \mathrm{hPa}$ and overcast conditions in icesaturated air at $210 \mathrm{~K}$. The downdraught speed is fixed to a value of $4 \mathrm{~cm} \mathrm{~s}^{-1}$. The cloud is assumed to consist of many small crystals $\left(n=0.2 \mathrm{~cm}^{-3}, r=20 \mu \mathrm{m}\right)$ in Figure 13(a) and (b), and few large crystals $(n=$ $\left.0.002 \mathrm{~cm}^{-3}, r=100 \mu \mathrm{m}\right)$ in Figure 13(c) and (d). These mean particle sizes correspond to small and large ice modes, respectively, found in midlatitude cirrus (Ivanova et al., 2001; Lawson et al., 2006). Small ice modes originate from homogeneous freezing and are predominantly observed in upper cloud layers, where supersaturation levels are highest (Miloshevich and Heymsfield, 1997). Large ice modes are typically observed in lower cloud regions and are fed by sedimenting and aggregating ice crystals. Early heterogeneous nucleation of few ice nuclei may also contribute to large ice modes.

The solid curves assume the ice crystals to be monodisperse, while the dashed curves prescribe a Gamma 
(a)

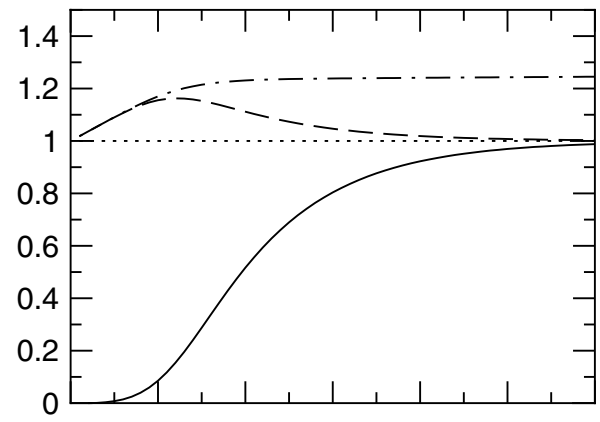

(c)

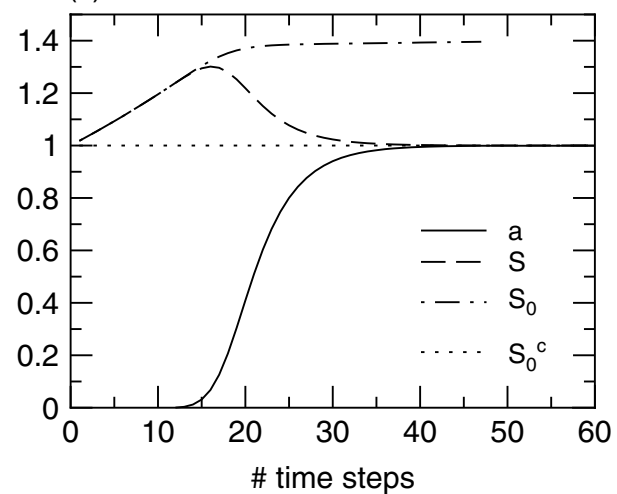

(b)

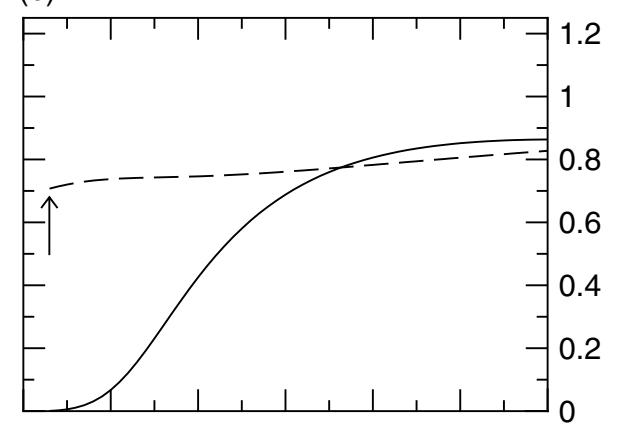

(d)

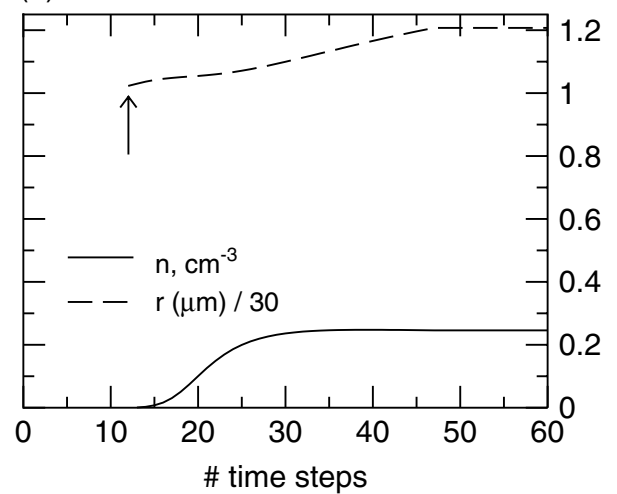

Figure 12. Temporal evolution of cirrus cloud formation by homogeneous freezing, showing the cloud fraction $a$, grid-mean ice saturation ratio $S$, ice saturation ratios inside cloud $S_{0}^{\mathrm{c}}$, and in clear sky $S_{0}$, grid-mean ice crystal concentration $n$, and mean number radius of ice crystals $r$. Values of $n$ are given in particles $\mathrm{cm}^{-3}$ of air and values of $r(\mu \mathrm{m})$ are divided by 30 to fit the same scale. The calculations start at $p_{0}=250 \mathrm{hPa}$, $T_{0}=230 \mathrm{~K}$, and in clear sky initially, and assume a constant updraught speed of $1 \mathrm{~cm} \mathrm{~s}^{-1}$. The standard deviation $\delta T$ of mesoscale temperature fluctuations is $(\mathrm{a}, \mathrm{b}) 1 \mathrm{~K}$ and $(\mathrm{c}, \mathrm{d}) 0.5 \mathrm{~K}$. Arrows in (b) and (d) indicate the first nucleation event. The updraught stops when $a=1$; $S_{0}$ is only defined up to this point.

size distribution with a fixed dispersion parameter, as detailed in Appendix C. Both sets of curves given in Figures 13(b) and (d) show a very similar behaviour. The grid-mean cloud ice content, $S_{\mathrm{i}}=q_{\mathrm{i}} / q_{\text {sat }}$, decreases continuously and vanishes completely for monodisperse crystals after the last time steps. A small amount of cloud ice remains for the polydisperse crystal population, because the assumed size distribution has no finite upper limit. Naturally, this amount is larger in the large-mode case. The diagnosed clear-sky $S_{0}$ decreases upon warming, assuming final values $\sim 0.4$.

More significant differences between small and large ice modes and between assumed ice crystal size distributions are seen in Figures 13(a) and (c). The imposed warming causes the gas phase saturation ratios $S_{0}^{\mathrm{c}}$ and $S$ to decrease via rising $q_{\text {sat }}$. On the other hand, $\mathrm{H}_{2} \mathrm{O}$ evaporates from the ice crystals, which tends to increase $S_{0}^{\mathrm{c}}$ and restore saturated conditions. The grid-mean ice saturation ratio $S$ follows the evolution of $a$ and $S_{\mathrm{i}}$ and does not differ for mono- or polydisperse cases. According to our results, ice may be present even at quite subsaturated conditions with $S_{0}^{\mathrm{c}} \approx 0.6$. Ice crystals may fall more than $5 \mathrm{~km}$ through clear air (Braham and Spyers-Duran, 1967). The existence of ice crystals at $S_{0}^{\mathrm{c}} \approx 0.6-0.8$ is supported by a comprehensive theoretical study, which in turn was found to be in good agreement with field observations (Hall and Pruppacher, 1976).
In the small-mode case (Figure 13(a)), $S_{0}^{\mathrm{c}}$ stays very close to saturation for monodisperse particles, indicating that equilibration is rapid and effectively compensates the warming-induced decrease in $S_{0}^{\mathrm{c}}$. This occurs because the ice crystal number density $n$ stays constant (apart from slight adiabatic changes) until all crystals vanish. In terms of Equation (22a), this implies a strong forcing $\Delta q_{\mathrm{v}}^{\mathrm{c}} \simeq q_{\mathrm{sat}}-q_{\mathrm{v}}^{\mathrm{c}}$. The dimensionless parameter $\xi$ from Equation (27) controlling the decay of $a$ and $S_{\mathrm{i}}$ is relatively large in this case. For polydisperse particles (dashed curves), $S_{0}^{\mathrm{c}}$ eventually falls below unity, because fewer and fewer crystals remain and $n$ never becomes zero. The increase in $S_{0}^{\mathrm{c}}$ caused by ice evaporation cannot compete with the decrease of $S_{0}^{c}$ forced by the increase in $q_{\text {sat }}$ due to warming, because the equilibration time-scale $\tau_{S} \propto 1 /(n r)$ increases steadily. Accordingly, $\xi$ remains small and $a$ does not reach zero. In a full GCM, sedimentation of such ice crystals would rapidly remove the remaining cloud ice and drive $a$ to zero.

The evolution is different if only few, large ice crystals sublimate, as shown in Figure 13(c). The time-scale $\tau_{S}$ is now generally much longer (by a factor $(0.2 \times$ $20) /(0.002 \times 100)=20$ initially) than in the small-mode case, implying only weak forcings $\Delta q_{\mathrm{v}}^{\mathrm{c}} \ll q_{\mathrm{sat}}-q_{\mathrm{v}}^{\mathrm{c}}$ and small $\xi$ values as long as $S_{\mathrm{i}}$ is high. This fact explains the differences seen between Figures 13(a) and (c). Again, 
(a)

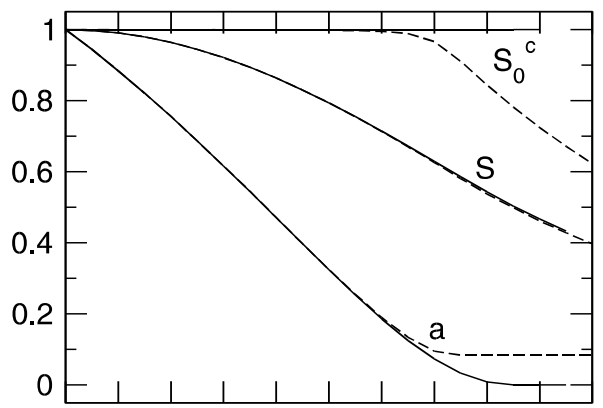

(c)

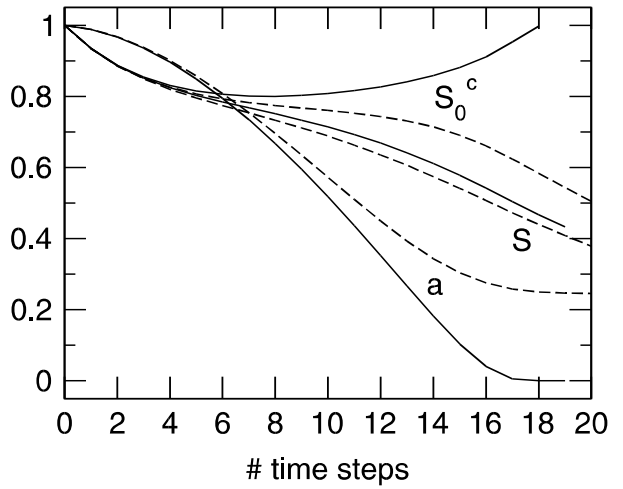

(b)

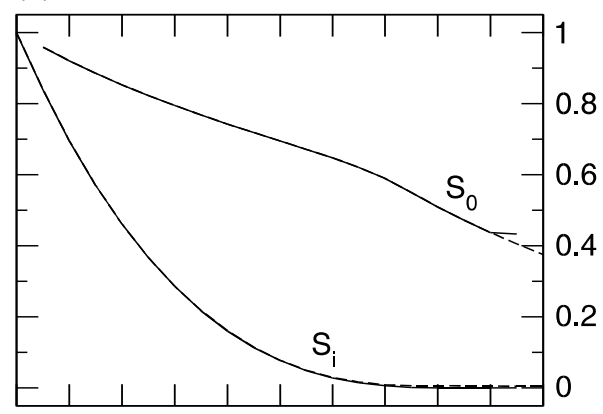

(d)

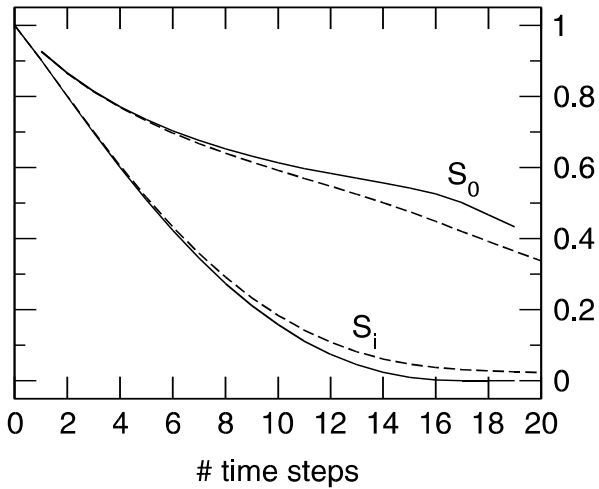

Figure 13. Temporal evolution of cirrus cloud decay with $T_{0}=210 \mathrm{~K}$, showing the grid-mean cloud ice contents expressed as saturation ratios, $S_{\mathrm{i}}$. The air subsides at a constant speed $4 \mathrm{~cm} \mathrm{~s}^{-1}$ and initially contains $(\mathrm{a}, \mathrm{b}) 0.2 \mathrm{~cm}^{-3}$ ice crystals with mean number radii $20 \mu \mathrm{m}$ and $(\mathrm{c}, \mathrm{d})$ corresponding values $0.002 \mathrm{~cm}^{-3}$ and $100 \mu \mathrm{m}$. Dashed curves are based on ice crystals distributed according to a Gamma spectrum with a dispersion parameter $\mu=3$, and solid curves are for monodisperse ice crystals. Clear-sky values $S_{0}$ are only defined for $a<1$.

we observe characteristic differences in the evolution of $a$ and $S_{0}^{\mathrm{c}}$ between mono- and polydisperse ice crystals that are brought about by an instantaneous versus continuous reduction in $n$. For example, $S_{0}^{c}$ rises again for monodisperse particles (solid curve in Figure 13(c)) because, due to constant $n, \tau_{S}$ increases less rapidly than in the polydisperse case and therefore ice evaporation prevails.

We note that the decay rates inferred from the solution given in Appendix $\mathrm{C}$ are upper limits, because there we have kept $S_{0}^{\mathrm{c}}$ fixed. In the calculations underlying Figure 13, we apply these solutions, but additionally take into account that $\left(S_{0}^{\mathrm{c}}-1\right)$ relaxes to saturation within the time step according to $\tau_{S}$ from Equation (5), giving a reduced value for the subsaturation in the next time step. This renders the differences in the evolution between monodisperse and polydisperse cases from Figure 13 smaller than suggested by Figure C.1(b).

In summary, the proposed cloud scheme produces gridmean ice supersaturations, ice crystal number densities and radii consistent with the processes controlling homogeneous ice nucleation and growth. Peak supersaturation and the rate of change of cloud fraction are largely controlled by the cooling rates prevailing on the subgrid scale. For cirrus generated by homogeneous freezing, $\mathrm{H}_{2} \mathrm{O}$ vapour inside newly formed cloud regions rapidly equilibrates with the ice phase at the point of cloud formation. The scheme further provides a realistic description of cirrus decay. Substantial in-cloud subsaturations occur predominantly in dissipating cloud layers, where few large crystals sublimate. As a first step, the assumption of monodisperse ice crystals is capable of reproducing the salient features of cloud changes.

\section{Future developments}

\subsection{Implementation in GCMs}

Our process-oriented approach for the consistent prediction of ice supersaturation, microphysics, and fractional coverage of cirrus clouds from statistical distributions of total water can be combined with cloud microphysical modules that predict resolved vapour, liquid, and ice concentrations separately. Besides a prognostic cloud fraction, the addition of in-cloud water vapour as a further prognostic variable is proposed. The ice number variable could be abandoned (with the saturation relaxation time-scale then expressed in terms of ice mass), but facilitates the coupling with two-moment microphysical schemes that are based on mass and number of cloud particles. As the homogeneous freezing process is rather insensitive to assumptions about the freezing aerosol particles, and only a small fraction of liquid aerosol particles freeze during cirrus formation, our cloud scheme can be employed in global models even without explicit aerosol representation. The information about subgridscale variability of vapour and cloud ice provided by our approach can be used in other large-scale model components, which is particularly relevant for radiation and 
microphysical processes (Pincus and Klein, 2000; Pincus et al., 2003).

Our cloud scheme framework permits the separate treatment of stratiform ice clouds from different sources, provided their cloud fractions and ice water (and crystal number) concentrations are tracked individually. Additional sources include anvil ice detrained from convective outflow, contrail cirrus generated by aircraft, and freezing water droplets lofted from mixed-phase clouds. While these additional source terms differ from cirrus formed by in situ nucleation processes as described here, all other terms from the cloud scheme could be directly applied. Missing processes for cloud evolution could easily be added, e.g. horizontal spreading rates for anvil and contrail cirrus that enhance the cloud coverage in regions with large horizontal wind shear. All of these cirrus clouds compete for the available clear-sky cloud fraction and in-cloud water vapour in each model grid cell. We underscore that such a treatment has a large potential to substantially improve the simulation of radiative response and cloud feedbacks by providing characteristic microphysical and optical properties for each cirrus type.

Our scheme needs to be coupled with a host scheme that covers all (liquid, mixed-phase, and ice) cloud types. Such a scheme should at least predict the cloud fraction, as for instance the process-based scheme of Tiedtke (1993) along with subsequent improvements (Gregory et al., 2000; ECMWF, 2004; Tompkins et al., 2007). Our approach could also be combined with a pure statistical cloud scheme, such as that of Tompkins (2002), in which cloud processes are solely formulated in terms of budget equations for PDF moments. This scheme can be expanded to include subgrid-scale temperature fluctuations (Tompkins, 2003) and to predict cloud fraction and consider explicit ice supersaturation. However, it remains to be shown whether all relevant cirrus processes discussed in our work can easily be reconciled with the single total water PDF.

\subsection{Subgrid-scale dynamical forcing}

In our cloud scheme, the clear-sky PDF of ice saturation ratio is determined by the standard deviation of MTF. If the global model resolution was increased so that clouds were resolved, the unresolved components of $\delta T$ would tend to zero. The clear-sky PDF then approaches a $\delta$ function, which is a desired property. However, the relevant fluctuations are not resolved even by the most advanced weather forecast models, and means to predict the corresponding gravity wave amplitudes consistently in a GCM framework are not yet available. We therefore see a timely research need to develop a self-consistent parametrization of MTF in a GCM and to validate (or constrain) the resulting MTF properties by available measurements. This adds to ongoing research efforts concentrating on direct orographic wave forcing (Dean et al., 2007). Scaling a subgrid-scale component of the vertical updraught speed based on the turbulent kinetic energy budget such that realistic cirrus properties are obtained is not considered a final solution (Lohmann and Kärcher, 2002).

It is possible that clear-sky fluctuations of water vapour uncorrelated with temperature fluctuations are relevant for estimating the increase in fractional cirrus cover (Appendix B). There also exist water vapour perturbations that are correlated with temperature perturbations altering the local saturation vapour pressure (Sommeria and Deardorff, 1977). Both should be included in a complete model.

Unlike in a pure statistical scheme, the moments of our in-cloud PDF do not explicitly depend on variables that characterise the subgrid-scale variability of total water and temperature. Instead, they are determined by the mean values of vapour and ice content. This dependence, while straightforward to implement and apply in a GCM, possibly introduces an unwanted dependence on horizontal resolution, which is difficult to quantify.

Future improvements of the scheme should base the in-cloud PDF on knowledge of total water and temperature fluctuations and might also consider a non-uniform in-cloud vapour PDF. The ultimate goal, however, should be a consistent representation of subgrid-scale temperature and total water variability in GCMs in clear-sky and cloudy regions for inclusion in a statistical cloud scheme.

\subsection{Consistency between microphysics and radiation}

With the use of mass and number of ice crystals to represent cloud variables in global models, the question arises whether a monodisperse approximation suffices to evaluate microphysical process rates and radiative properties. The need to consider particle size dispersion to evaluate microphysical process rates has been recognised in mesoscale models (Harrington et al., 1995). Here, we have studied the effects of monodisperse versus polydisperse assumptions for the sublimation of ice crystals and found differences in terms of cloud cover evolution during cirrus decay (section 4). While these differences remain relatively small (as they will be in case of depositional growth), the monodisperse assumption might cause significant error when sedimentation velocities and aggregation rates are to be calculated.

Furthermore, it is obvious that a realistic effective ice crystal radius for use in short-wave radiation schemes cannot be estimated without knowledge about particle size dispersion. Therefore, a consistent prediction of precipitation and radiative forcing is only possible when appropriate assumptions about ice crystal size distributions are made. Such assumed size distributions, constrained by the predicted number and mass of the cloud particles, could be used to average over the optical properties of single ice crystals for which comprehensive databases are available (Yang et al., 2000, 2005).

Most GCMs with purely mass-based cloud schemes parametrize microphysical and radiative properties in terms of ice water content. The generalization of such parametrizations by means of assumed ice crystal size distributions for use in two-moment schemes, which we call 
a pseudo-spectral approach, is not trivial, although such schemes better constrain the effective ice crystal radius. For instance, when monodisperse crystals sublimate, their mean size decreases and their number stays constant, while the use of a Gamma distribution causes their number to decrease and their mean size to actually increase (Appendix C). This may perhaps be relevant for the calculation of the cirrus radiative properties during the decay phase. We therefore recommend developing a consistent pseudo-spectral approach for microphysics and radiation, which additionally takes advantage of the subgrid-scale variability provided by the total water PDFs.

\subsection{Heterogeneous ice nucleation}

We mention two reasons for not yet including effects of heterogeneous ice nuclei (IN) in the present version of our cloud scheme. First, heterogeneous IN are unlikely to control cirrus formation in many cases (section 2.1). Important properties such as the total ice crystal number density and the effective radius are expected to be largely controlled by homogeneous freezing. There is no observational evidence available in support of high concentrations of IN with low nucleation thresholds in background conditions.

Second, the concentration and properties of heterogeneous IN are only poorly characterized observationally (DeMott et al., 2003) and their predictability in current global models is limited (Lohmann et al., 2004). We nevertheless recognise that even few IN (on the order of 10 per litre of air) could affect frequency of occurrence, optical properties, and development of cirrus. Numerical simulations suggest that, despite an earlier onset of ice nucleation, the cirrus lifetime is not necessarily longer and the coverage is not always larger compared to cases where IN are absent (Haag and Kärcher, 2004).

We therefore leave the inclusion of IN in our proposed cloud scheme for future work. The formal inclusion of their effects on fractional cirrus cover and microphysics is possible using the full cirrus parametrization including IN (Kärcher et al., 2006). This scheme has been developed to enable realistic simulations of possible indirect effects of aerosols on cirrus clouds. However, each IN type produces a separate class of ice crystals whose masses (and numbers) are to be predicted separately. This adds considerable complexity due mainly to an increased number of microphysical interactions.

\section{Summary}

We have presented a statistical cloud scheme for nonconvective cirrus to predict horizontal cloud fraction, grid-mean and in-cloud water vapour, ice water content, and ice crystal number density for use in GCMs in a selfconsistent manner. In this scheme, cirrus clouds grow and decay under the action of large-scale ascent and descent, but cirrus microphysical properties are determined by mesoscale temperature fluctuations. The scheme does not rely on equilibrium assumptions nor employs saturation adjustment, hence both ice sub- and supersaturations are allowed to occur in clear-sky and cloudy air. Growth and sublimation rates of ice crystals are controlled by vapour diffusion.

Cloud fraction and cloud variables are consistently derived from separate probability distributions of total water in the cloudy and cloud-free portion of a largescale model's grid cell. These distributions contain important information on the subgrid-scale variability of cloud ice and clear-sky relative humidity. Their specific functional forms are guided by in situ observations of cirrus parameters and physical processes. The higher distribution moments are not predicted, but are parametrized in terms of variables carried by the global model, and may vary both geographically and temporally.

The clear-sky water distribution is used to determine the increase in fractional coverage due to cirrus ice formation. Its mean value and moments are determined by the diagnosed environmental relative humidity, whose upper limit coincides with the freezing threshold, and by the magnitude of mesoscale temperature fluctuations that are crucial for the freezing process.

Cirrus formation predominantly occurs via homogeneous freezing of liquid-containing aerosol particles. This process is controlled by the same temperature fluctuations used to predict the corresponding cloud fraction changes. This emphasises that processes determining the microand macrophysical properties of cirrus clouds are treated self-consistently in the scheme. A simple yet accurate parametrization of homogeneous freezing is employed that can be generalized to include more complicated ice nucleation pathways in the future.

The total water distribution inside cirrus is used to compute the decrease in cloud fraction once cloudy air becomes subsaturated with respect to ice. Water vapour inside cloud and cloud ice content are separate prognostic variables. The distribution of in-cloud vapour is approximated by a homogeneous distribution, which may, however, deviate from saturation. As horizontal variability in ice water content is an important factor for the radiative impact of cirrus, cloud ice variability is taken into account. The variance of the statistical distribution of cloud ice is determined by the mean ice water content, which, in turn, depends on the magnitude of sub- and supersaturations tracked in cloudy air.

Apart from further refinements and extensions, application of the scheme in a GCM requires its combination with an appropriate host cloud scheme that also covers other cloud types. Together, this will result in further processes affecting the cirrus cloud and moisture variables (e.g. sedimentation, aggregation, advective and diffusive transport), which couple back to the predicted cirrus cloud fraction via changes of parameters controlling the properties of the clear-sky and in-cloud probability distributions of total water. Such a combined cloud scheme is an essential prerequisite to predicting cirrus clouds globally and to study their role in climate change scenarios in future work, both taking into account dynamical changes in cirrus formation and changes in ice-nucleating aerosol abundance and composition. 


\section{Acknowledgements}

A preliminary outline of the cirrus scheme was presented at the ECMWF Workshop on Parametrization of Clouds in Large-scale Models (Reading, UK, November 2006). We thank Beiping Luo for providing us with MTF time series and George Craig for constructive discussions.

\section{Appendix A. \\ Analytical solution for homogeneous freezing and initial growth}

We derived a simple analytical solution for the generation of ice crystals by homogeneous freezing of monodisperse aerosol particles. This solution yields the ice crystal number density $n$ and radius $\widehat{r}$ after the freezing event (at $\tau_{\mathrm{f}}$ ). We recall the key equations below, and refer to Kärcher and Lohmann (2002) for details.

The solution is governed by the two dimensionless parameters $\kappa$ and $\delta$,

$$
\kappa\left(r_{\mathrm{p}}, \omega\right)=2 \beta \frac{\tau_{\mathrm{f}}}{\tau_{\mathrm{g}}}, \quad \delta\left(r_{\mathrm{p}}\right)=\frac{r_{\mathrm{p}}}{r_{\star}},
$$

where $\beta\left(r_{\mathrm{p}}\right)=\delta /(1+\delta)$ and $r_{\star}=4 D /(s u)$ is a characteristic radius for which gas kinetic and diffusive effects on the ice crystal growth rate are equally important, $D$ is the diffusion coefficient of $\mathrm{H}_{2} \mathrm{O}$ molecules in air, $u$ is their mean thermal speed, and $s$ is the deposition coefficient of $\mathrm{H}_{2} \mathrm{O}$ on ice surfaces $(s=0.5$ in Figure 1). The time-scales for freezing $\tau_{\mathrm{f}}$ and initial growth of the nucleated ice particles $\tau_{\mathrm{g}}$ as displayed in Figure 1(b) are given by

$$
\begin{aligned}
\tau_{\mathrm{f}}^{-1} & =c_{2}\left\{304.4+\left(\frac{T}{250}-2\right) T\right\} \omega, \quad c_{2}=1.5, \\
\tau_{\mathrm{g}}^{-1} & =v \frac{D \beta}{r_{\mathrm{p}}^{2}} \frac{p_{\mathrm{sat}}}{k_{\mathrm{B}} T}\left(S_{\mathrm{cr}}-1\right)
\end{aligned}
$$

where $v$ is the volume of an $\mathrm{H}_{2} \mathrm{O}$ molecule in bulk ice. The numerical values except $c_{2}$ in Equation (A.2a) (with $T$ in units of $\mathrm{K}$ to obtain $\tau_{\mathrm{f}}$ in units of $s$ ) are taken from Ren and MacKenzie (2005).

With Equation (A.1), $n$ and $\widehat{r}$ are given by

$$
\begin{aligned}
n= & \frac{S_{\mathrm{cr}}}{S_{\mathrm{cr}}-1} \frac{(\theta / T)-\gamma}{4 \pi r_{\star} D} \frac{\omega}{T} \\
& \times\left\{\delta-1+\frac{1}{\delta+1}\left(\frac{(\delta+1)^{2}}{2}+\frac{1}{\kappa}\right) f(\kappa)\right\}^{-1} \leq n_{\mathrm{p}}, \\
\widehat{r}= & r_{\star}\left\{(\delta+1)\left(1+\frac{f(\kappa)}{2}\right)-1\right\} \geq r_{\mathrm{p}},
\end{aligned}
$$

where $\gamma=7 / 2$ is the ratio of heat capacity at constant pressure and universal gas constant and

$$
f(\kappa)=(\pi \kappa)^{1 / 2} \exp \left(\kappa^{-1}\right)\left\{1-\operatorname{erf}\left(\kappa^{-1 / 2}\right)\right\} .
$$

In many situations, growth proceeds faster than nucleation $(\kappa \gg 1)$, and the dependence on initial particle size via $\delta$ drops out; we obtain the scaling laws $n \propto \omega^{3 / 2}$, $\widehat{r} \propto \omega^{-1 / 2}$, and $\tau_{S} \propto \omega^{-1}$. The time-scale $\tau_{S}$ is defined in Equation (5). These relationships already provide good approximations to the full solution for polydisperse aerosols.

The freezing parametrization additionally calculates the subsequent diffusional growth of the newly formed ice crystals within a prescribed time interval $\Delta t$ after freezing. For this purpose, an analytical solution is employed that yields the final mean radius $\bar{r}=r(\Delta t) \geq \widehat{r}$ the crystals achieve after isothermal growth from $S_{\mathrm{cr}}$ towards $S=1$. The solution is given implictly in scaled form, where $\bar{x}=\bar{r} / r_{\max }, \widehat{x}=\widehat{r} / r_{\max }$, and the parameter $x_{\star}=r_{\star} / r_{\max }$ employ the maximum possible ice crystal radius,

$$
r_{\max }=\left\{\widehat{r}^{3}+\frac{3 v}{4 \pi n} \frac{p_{\mathrm{sat}}}{k_{\mathrm{B}} T}\left(S_{\mathrm{cr}}-1\right)\right\}^{1 / 3},
$$

and $y=\Delta t \cdot 4 \pi n D r_{\max } / 3$ represents the scaled given time interval,

$$
\begin{aligned}
y= & \left(x_{\star}+1\right)\left\{\mathcal{I}_{1}(\bar{x})-\mathcal{I}_{1}(\widehat{x})\right\} \\
& +\left(x_{\star}-1\right)\left\{\mathcal{I}_{2}(\bar{x})-\mathcal{I}_{2}(\widehat{x})\right\}, \\
\mathcal{I}_{1}(x)= & \frac{1}{6} \ln \left\{\frac{1+x+x^{2}}{(1-x)^{2}}\right\}, \\
\mathcal{I}_{2}(x)= & \frac{1}{\sqrt{3}} \arctan \left(\frac{1+2 x}{\sqrt{3}}\right) .
\end{aligned}
$$

Appendix B.

Impact of clear-sky water vapour changes on the ice saturation ratio

As a working assumption, we have opted to neglect both adiabatic corrections and the variability of $p_{\mathrm{v}}$ relative to the variability of $T$ to determine the properties of the clear-sky distribution $\mathrm{d} P_{S} / \mathrm{d} S$. For small $\delta T$ when the tail of this distribution (or $f$ ) is steeply rising, its slope is sensitive to additional fluctuations induced by subgridscale water vapour variability. Below, we make a simple attempt to quantify the relative influence of variability in $T$ and $p_{\mathrm{v}}$ on $f$.

We first quantify the impact of adiabatic changes of $p_{\mathrm{v}}$ in isolation. The rate of change of $S$ in an adiabatically rising air parcel in the absence of nucleation, condensation, or mixing with ambient air is given by

$$
\frac{\mathrm{d} S}{\mathrm{~d} t}=-S\left(\frac{\theta}{T^{2}}-\frac{\gamma}{T}\right) \frac{\mathrm{d} T}{\mathrm{~d} t} .
$$

Equation (B.1) can be integrated to give

$$
S(T)=S\left(T_{0}\right) \exp \left\{\gamma \ln \left(\frac{T}{T_{0}}\right)+\theta\left(\frac{1}{T}-\frac{1}{T_{0}}\right)\right\} .
$$

The first (logarithmic) term in the exponent of Equation (B.2) accounts for adiabatic changes of $p_{\mathrm{v}}$, while the second term stems from temperature changes. In 
a cooling event $\left(T<T_{0}\right)$, the adiabatic $p_{\mathrm{v}}$ change counteracts the increase in $S$ caused by the pure temperature change. Evaluating the ratio $z$ of the two terms for small deviations from the base state, i.e. $T=T_{0} \pm \delta T$ with $\delta T \ll T_{0}$, yields $|z| \simeq \gamma T_{0} / \theta<0.134$ for $T_{0}<235 \mathrm{~K}$.

Changes in clear-sky $S$ arise from the combined action of temperature fluctuations, associated adiabatic changes, and fluctuations of the water vapour partial pressure $p_{\mathrm{v}}$. Discretising Equation (B.1) around a mean state $\left\{S_{0}, T_{0}\right\}$ and adding fluctuations $\delta p_{\mathrm{v}}>0$ around the mean value $p_{\mathrm{v} 0}=S_{0} p_{\mathrm{sat}}\left(T_{0}\right)$ that are uncorrelated with $\delta T$ leads to

$$
\frac{\delta S}{S_{0}}=-\left(\frac{\theta}{T_{0}}-\gamma\right) \frac{\delta T}{T_{0}}+\frac{\delta p_{\mathrm{v}}}{p_{\mathrm{v} 0}} .
$$

With Equation (B.3) it follows that water vapour fluctuations become more important in determining $\delta S$ than temperature fluctuations when

$$
\frac{\delta p_{\mathrm{v}}}{p_{\mathrm{v} 0}}>\left(\frac{\theta}{T_{0}}-\gamma\right) \frac{\delta T}{T_{0}} \simeq \frac{\theta}{T_{0}^{2}} \delta T
$$

regardless of $S_{0}$. Inserting $T_{0}=225 \mathrm{~K}$ and $\delta T=1$ (0.5) $K$ gives $\delta p_{\mathrm{v}} / p_{\mathrm{v} 0}>0.1(0.05)$. Equation (B.4) also shows that the influence of fluctuations of water vapour relative to temperature tends to be of greater importance in the lower troposphere, where $T_{0}$ is larger.

We now study the impact of combined vapour and temperature changes on the fraction $f$ of the clearsky PDF above the homogeneous freezing threshold $S_{\mathrm{cr}}$. We convolved numerically Gaussian random PDFs of $p_{\mathrm{v}}$ with a standard deviation $\sigma_{\mathrm{v}}=\delta p_{\mathrm{v}}$, and of $T$ from Equation (2). Adiabatic changes are included via $p_{\mathrm{v}}=$ $p_{\mathrm{v} 0}\left(T / T_{0}\right)^{\gamma}$. We computed the fraction of the distribution above $S_{\text {cr }}$, denoted by $f^{\prime}$, and compare it with $f$ from Equation (12), which includes only the effect of temperature changes on $p_{\text {sat }}(T)$.

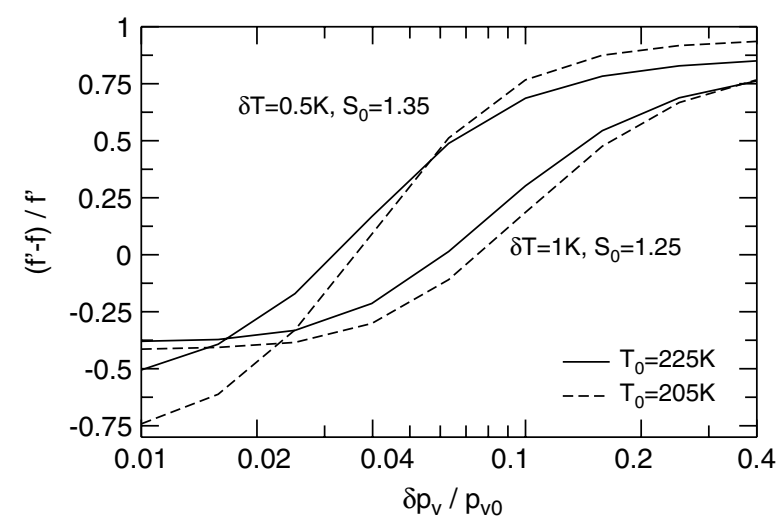

Figure B.1. Relative change in the fraction of the clear-sky distribution of $S$ above the homogeneous freezing threshold versus assumed water vapour fluctuations around the mean $\mathrm{H}_{2} \mathrm{O}$ partial pressure $p_{\mathrm{v} 0}$. The term relative indicates the difference between a calculation including mesoscale fluctuations of $T$ and $p_{\mathrm{v}}$ and adiabatic changes in $p_{\mathrm{v}}$, and a calculation with only $T$ fluctuations, normalised by the former. Curves are shown for different choices of clear-sky mean values $S_{0}$ and mesoscale temperature standard deviations $\delta T$, each for two different mean temperatures $T_{0}$.
Figure B.1 shows $\left(f^{\prime}-f\right) / f^{\prime}$ versus $\left(\delta p_{\mathrm{v}} / p_{\mathrm{v} 0}\right)$ for two different pairs $\left\{S_{0}, \delta T\right\}$ for which $f \simeq 0.05$, and for two different $T_{0}$. We see that $f^{\prime}$ rises with rising $\left(\delta p_{\mathrm{v}} / p_{\mathrm{v} 0}\right)$, because fluctuations of $\mathrm{H}_{2} \mathrm{O}$ vapour lead to a broadening of the PDF of $S$. For increased $\delta T$, higher $\left(\delta p_{\mathrm{v}} / p_{\mathrm{v} 0}\right)$ values are required for $\mathrm{H}_{2} \mathrm{O}$ changes to become as effective in controlling $f^{\prime}$ as the changes in $T$, for which reason the curves shift to the right. When $f^{\prime}<f$, the $\mathrm{H}_{2} \mathrm{O}$ fluctuations are too small to overcompensate the effect of adiabatic changes, i.e. a narrowing of the PDF. Hence, for the lowest values of $\left(\delta p_{\mathrm{v}} / p_{\mathrm{v} 0}\right)$ we discover the pure effect of adiabatic $p_{\mathrm{v}}$ changes, which in turn become unimportant for large $\mathrm{H}_{2} \mathrm{O}$ fluctuations. These results confirm the estimate from Equation (B.4) and show that $\delta p_{\mathrm{v}} / p_{\mathrm{v} 0}>0.1(0.05)$ leads to a non-negligible effect (i.e. $\left|f^{\prime}-f\right| / f^{\prime}>0.25$ ) for $\delta T=1(0.5) \mathrm{K}$.

In the range $\delta p_{\mathrm{v}} / p_{\mathrm{v} 0} \simeq 0.03-0.08$, the effects of $\mathrm{H}_{2} \mathrm{O}$ fluctuations and adiabatic changes approximately compensate each other and in that case we may regard Equation (12) as a reasonable approximation for $f$. For larger (smaller) fluctuations of $\mathrm{H}_{2} \mathrm{O}, f$ tends to underestimate (overestimate) the true value $f^{\prime}$. For a given $\delta p_{\mathrm{v}}$, the exact difference between $f^{\prime}$ and $f$ depends on $T_{0}, S_{0}$, and $\delta T$. In particular, when $S_{0}$ and $\delta T$ (hence $f$ ) are small, the results become very sensitive to small changes in $\delta p_{v}$, because of the steepness of the PDF near $S_{\mathrm{cr}}$. Regardless, because of the compensating effects, accounting for $p_{\mathrm{v}}$ changes is only meaningful if adiabatic corrections and fluctuations of $p_{\mathrm{v}}$ are introduced at the same time.

Gierens et al. (2007) analysed instantaneous temperature and moisture fluctuations based on 9 years of aircraft data. The annual mean temperature fluctuations (averaged over all relative humidities) are $0.82 \mathrm{~K}$ in T42 resolution at an average $T_{0}=220 \mathrm{~K}$, well within the range of MTF values discussed here. The corresponding relative moisture fluctuations are $\delta p_{\mathrm{v}} / p_{\mathrm{v} 0}=0.18$ at a mean $S_{0} \simeq 0.7$, but decrease substantially to values near 0.1 at $S_{0}=1.3$. The latter figures are comparable to those shown in Figure B.1, showing that water vapour fluctuations begin to affect our calculated increases in cloud fraction only in regions where MTF amplitudes are low $\left(\delta T<1 \mathrm{~K}\right.$ for $S_{0}=1.3$ and $\left.T_{0}=225 \mathrm{~K}\right)$.

\section{Appendix C.}

\section{Ice crystal size distributions in dissipating cirrus}

A single spherical ice crystal $(C=1)$ changes its radius by vapour diffusion according to

$$
\frac{\mathrm{d} r}{\mathrm{~d} t}=v \frac{D}{r} \beta C \phi \frac{p_{\mathrm{sat}}}{k_{\mathrm{B}} T}\left(S_{0}^{\mathrm{c}}-1\right) .
$$

Equation (C.1) is consistent with Equation (20). For the sake of argument, we additionally set $\beta=\phi=1$ and obtain the solution for constant $S_{0}^{\mathrm{c}}$ and $T$,

$$
r(t)=\sqrt{r_{0}^{2}+2 G t}, \quad G=v D \frac{p_{\text {sat }}}{k_{\mathrm{B}} T}\left(S_{0}^{\mathrm{c}}-1\right),
$$


in which $r_{0}$ denotes the initial radius at $t=0$. In subsaturated conditions, $S_{0}^{\mathrm{c}}<1$ and $G<0$. Equation (C.2) is only defined up to times $r_{0}^{2} /(2|G|)$. For monodisperse ice crystals, the product $n r$ entering the sublimation rate time-scale $\tau_{S}$ from Equation (22a) is simply given by $n_{0} r(t)$, as $n=n_{0}$ does not change until the cloud completely dissipates.

The vapour and ice mass changes in an ensemble of ice crystals of different size are controlled by the size distribution average $<n r>(t)$. To estimate this average, we note the continuity equation governing the evolution of a number size distribution $F=\mathrm{d} n / \mathrm{d} r$ during growth or evaporation,

$$
\begin{aligned}
\frac{\partial F}{\partial t}+\frac{\partial}{\partial r}\left(\frac{\mathrm{d} r}{\mathrm{~d} t} \cdot F\right) & =0, \\
F(r, t=0) & =n_{0} \frac{\lambda^{\mu+1}}{\Gamma(\mu+1)} r^{\mu} \exp (-\lambda r) .
\end{aligned}
$$

Equation (C.3) is easily solved by the method of characteristics. The function $G F / r$ is constant along the characteristic curves (i.e. the particle radius trajectories), yielding the solution $F(r, t)=\left(r / r_{0}\right) F\left(r_{0}, 0\right)$. Using Equation (C.2) to eliminate $r_{0}$ from this solution and specifying $F\left(r_{0}, 0\right)$ as a Gamma distribution with total initial number density $n_{0}$, dispersion parameter $\mu$, and slope $\lambda$, we obtain

$$
\begin{aligned}
\frac{\mathrm{d} n}{\mathrm{~d} t}(r, t)=n_{0} & \frac{\lambda^{\mu+1}}{\Gamma(\mu+1)} r\left(r^{2}-2 G t\right)^{(\mu-1) / 2} \\
& \times \exp \left\{-\lambda\left(r^{2}-2 G t\right)^{1 / 2}\right\} .
\end{aligned}
$$

We set $T=225 \mathrm{~K}, \mu=3$, and $r_{0}=25 \mu \mathrm{m}$, which converts into $\lambda=(\mu+1) / r_{0}$ using the definition of the mean radius of the Gamma distribution. These choices are in the range of values of small particle modes measured in midlatitude cirrus clouds. Further, we prescribe a constant subsaturation $S_{0}^{\mathrm{c}}-1=-0.1$ and $D=0.75 \mathrm{~cm}^{2} \mathrm{~s}^{-1}$. This results in evaporation rates for particles of radius $r_{0}$ of $|G| / r_{0} \approx 1 \mu \mathrm{m} \mathrm{min}^{-1}$.

The resulting ice crystal size distributions are shown in Figure C.1(a) for different times after sublimation has set in. A typical feature is the evaporation tail, which develops very quickly (after $1 \mathrm{~min}$ ), because smaller crystals sublimate much faster than larger ones according to Equation (C.1). This tail is rather independent of the assumed analytic form of the initial size spectrum, which may help facilitate future parametrizations of the evaporation kinetics. The distribution shape does not significantly change thereafter, although the total number density of ice crystals $n(t)$ decreases according to

$$
n(t)=n_{0} \mathrm{e}^{-x_{0}} \sum_{m=0}^{\mu} \frac{x_{0}^{m}}{m !}, \quad x_{0}(t)=\sqrt{2|G| \lambda^{2} t},
$$

indicating a continuous loss of ice crystals, contrary to the monodisperse solution where $n=n_{0}$. Equation (C.5) follows from integration of Equation (C.4) for integer $\mu$ over all particle radii and is shown in Figure C.1(b) (dotted curve). In reality, the distributions would be cut off at small $r=r_{\mathrm{p}} \approx 0.25 \mu \mathrm{m}$, when individual crystal radii reach the sizes of the dry aerosol core upon which they originally nucleated, but this does not change our argument. Lowering or increasing $T$ would slow or enhance the sublimation process, but the results would be qualitatively similar.

Multiplying Equation (C.4) with $r$ and performing the integration yields the desired average $<n r>$ :

$$
<n r>(t)=\frac{n_{0} r_{0}}{\Gamma(\mu+2)} \int_{x_{0}}^{\infty} \sqrt{x^{2}-x_{0}^{2}} x^{\mu} \mathrm{e}^{-x} \mathrm{~d} x .
$$

This integral is solved numerically and is shown in Figure C.1(b) (solid), along with the monodisperse solution (dashed). While differences in $\left\langle n r>\right.$ and thus $\tau_{S}$ (a)

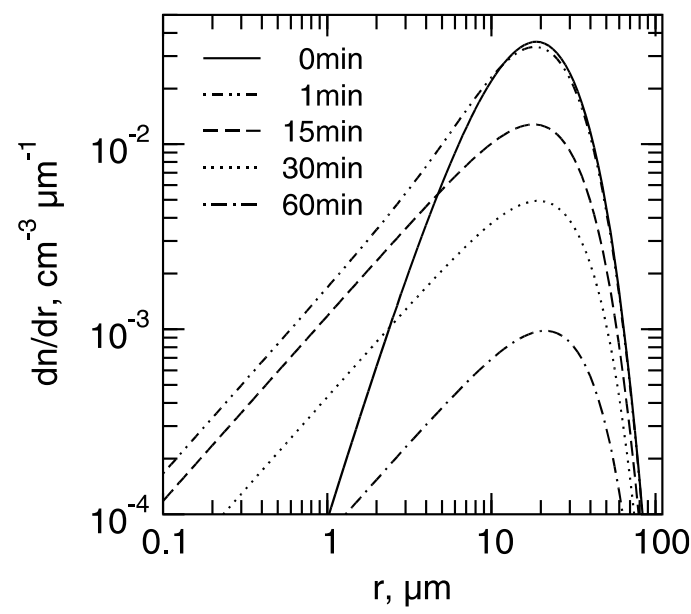

(b)

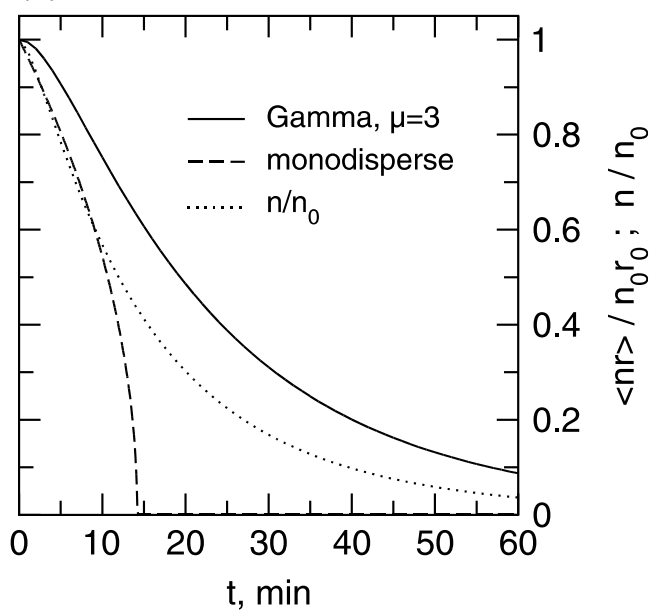

Figure C.1. (a) Evolution of an ice crystal size spectrum (Gamma distribution with parameter dispersion $\mu=3$, mean initial radius $r_{0}=25 \mu$ m, and total initial number density $n_{0}=1 \mathrm{~cm}^{-3}$ ) in subsaturated conditions at $T=225 \mathrm{~K}$. (b) Time history of the number concentration $n$ (dotted) and the product $n r$ (solid) averaged over the Gamma distribution, and $n r$ for the monodisperse spectrum (dashed) with the same $n_{0}$ and $r_{0}$. In the latter case, $n=n_{0}=$ constant. The subsaturation is fixed to $S_{0}^{\mathrm{c}}-1=-0.1$. All variables in (b) are scaled to initial values. 
are relatively small for $t<10 \mathrm{~min}$, it takes longer time to fully evaporate the larger crystals $\left(r>r_{0}\right)$ present in the Gamma distribution. We emphasise that keeping $S_{0}^{\mathrm{c}}$ fixed in this analytical solution maximises the difference between monodisperse and polydisperse solutions (section 4).

\section{Appendix D. Symbols used}

\begin{tabular}{|c|c|}
\hline$a$ & horizontal cirrus cloud fraction \\
\hline$c_{0}, c_{1}, c_{2}$ & constants \\
\hline$c_{\mathrm{i}}$ & mean ice crystal number mixing ratio \\
\hline$c_{p}$ & $\begin{array}{l}\text { specific heat capacity of air at con- } \\
\text { stant pressure }\left(=10^{7} \mathrm{erg} \mathrm{g}^{-1} \mathrm{~K}^{-1}\right)\end{array}$ \\
\hline$C$ & $\begin{array}{l}\text { ice crystal capacitance factor } \\
(\text { here }=1)\end{array}$ \\
\hline$D$ & $\begin{array}{l}\text { diffusion coefficient for water } \\
\text { molecules in air }\end{array}$ \\
\hline$f\left(S>S_{\mathrm{cr}}\right)$ & $\begin{array}{l}\text { fraction of clear-sky humidity distri- } \\
\text { bution above the homogeneous freez- } \\
\text { ing threshold }\end{array}$ \\
\hline$F$ & ice crystal number size distribution \\
\hline$g$ & $\begin{array}{l}\text { acceleration } \\
\left.9.81 \mathrm{~cm} \mathrm{~s}^{-1}\right)\end{array} \quad$ of gravity $\quad(=$ \\
\hline$g_{\star}\left(S>S_{\mathrm{cr}}\right)$ & $\begin{array}{l}\text { water vapour above homogeneous } \\
\text { freezing limit deposited on nucleated } \\
\text { ice crystals }\end{array}$ \\
\hline$G$ & ice crystal areal growth rate \\
\hline$k_{\mathrm{B}}$ & $\begin{array}{l}\text { Boltzmann constant } \quad(=1.38 \times \\
\left.10^{-16} \mathrm{erg} \mathrm{K}^{-1}\right)\end{array}$ \\
\hline$\ell$ & horizontal length-scale \\
\hline$m$ & local cirrus cloud ice water content \\
\hline$n$ & number density per unit volume of air \\
\hline $\mathcal{N}_{X}$ & normalisation factor for $\mathrm{d} P_{X} / \mathrm{d} X$ \\
\hline$p$ & $\begin{array}{l}\text { air pressure, partial pressure (with } \\
\text { subscript) }\end{array}$ \\
\hline $\mathrm{d} P_{X} / \mathrm{d} X$ & probability distribution function of $X$ \\
\hline$q$ & $\begin{array}{l}\text { mean total water mass mixing ratio, } \\
\text { mass mixing ratio (with subscript) }\end{array}$ \\
\hline$r, r_{\star}$ & $\begin{array}{l}\text { radius, radius above which ice deposi- } \\
\text { tional growth becomes diffusion lim- } \\
\text { ited }\end{array}$ \\
\hline$s$ & $\begin{array}{l}\text { deposition coefficient for water } \\
\text { vapour impinging on ice crystals } \\
\text { (here }=0.5 \text { ) }\end{array}$ \\
\hline$S, S_{\mathrm{cr}}$ & $\begin{array}{l}\text { saturation ratio with respect to ice, } \\
\text { homogeneous freezing threshold }\end{array}$ \\
\hline$S_{0}, S_{0}^{\mathrm{c}}$ & $\begin{array}{l}\text { mean ice saturation ratio: clear-sky } \\
\text { and inside cloud }\end{array}$ \\
\hline$t$ & time \\
\hline$T$ & air temperature \\
\hline$u$ & $\begin{array}{l}\text { mean thermal velocity of water } \\
\text { molecules }\end{array}$ \\
\hline$v$ & $\begin{array}{l}\text { specific volume of water molecules in } \\
\text { bulk ice }\end{array}$ \\
\hline$w$ & vertical wind speed \\
\hline$\alpha$ & $\begin{array}{l}\text { water vapour partial pressure divided } \\
\text { by } \vartheta\end{array}$ \\
\hline
\end{tabular}

Indices

a

c

e

g

$\mathrm{f}$

i

$j$ $\min , \max$ $\mathrm{p}$

sat

tot

v

0

$\widehat{.}$

$\bar{\cdots},<\cdot>$

\section{References}

Abramowitz M, Stegun IA. 1972. Handbook of Mathematical Functions. Dover Publications: New York.

Bacmeister JT, Eckerman SD, Tsias A, Carslaw KS, Peter T. 1999. Mesoscale temperature fluctuations induced by a spectrum of gravity gas kinetic correction factor entering the diffusional growth rate of ice crystals

adiabatic index in equation of state for air $(=7 / 2)$

dimensionless size parameter in homogeneous freezing model

standard deviation of mesoscale water vapour and temperature fluctuations ratio of molecular masses of water and air molecules $(=0.622)$

ice vapour pressure prefactor $(=$ $3.4452 \times 10^{10} \mathrm{hPa}$ )

Clausius-Clapeyron parameter for ice vapour pressure $(=6132.9 \mathrm{~K})$

dimensionless growth parameter in homogeneous freezing model

slope and dispersion parameters of Gamma distribution

dimensionless parameter controlling cirrus decay by sublimation

bulk mass density

standard deviation

full width of clear-sky humidity distribution

global model time step; time-scale (with subscript)

sub- or supersaturation relaxation time-scale

ice crystal ventilation factor (here $=1)$

cloud fraction weighted probability distribution function of humidity absolute value of cooling rate

air

inside cloud

in the cloud environment

growth

freezing

ice phase

integer $>0$

minimum, maximum value

aerosol particle

value at ice saturation

total

water vapour

initial value, mean value

value at the end of a homogeneous freezing event

average, average over ice crystal size distribution 
waves: A comparison of parameterizations and their impact on stratospheric microphysics. J. Atmos. Sci. 56: 1913-1924.

Braham RR, Spyers-Duran P. 1967. Survival of cirrus crystals in clear air. J. Appl. Meteorol. 6: 1053-1061.

Cantrell W, Heymsfield AJ. 2005. Production of ice in tropospheric clouds - A review. Bull. Am. Meteorol. Soc. 86: 795-807.

Carlin B, Fu Q, Lohmann U, Mace GG, Sassen K, Comstock JM. 2002. High cloud horizontal inhomogeneity and solar albedo bias. J. Climate 15: 2321-2339.

Chen T, Rossow WB, Zhang Y. 2000. Radiative effects of cloud-type variations. J. Climate 13: 264-286.

Cziczo DJ, DeMott PJ, Brooks SD, Prenni, AJ, Thomson DS, Baumgardner D, Wilson JC, Kreidenweis SM, Murphy DM. 2004. Observations of organic species and atmospheric ice formation. Geophys. Res. Lett. 31: L12116, doi:10.1029/2004GL019822.

Dean SM, Lawrence BN, Grainger RG, Heuff DN. 2005. Orographic cloud in a GCM: the missing cirrus. Clim. Dyn. 24: 771-780.

Dean SM, Flowerdew J, Lawrence BN, Eckermann SD. 2007. Parameterisation of orographic cloud dynamics in a GCM. Clim. Dyn. 28: 581-597.

DelGenio AD. 2002. GCM simulations of cirrus for climate studies. Pp. 310-326 in Cirrus, Lynch DK, Sassen K, Starr DO'C, Stevens G. (eds.) Oxford University Press, New York.

DeMott PJ, Cziczo DJ, Prenni AJ, Murphy DM, Kreidenweis SM, Thomson DS, Borys R. 2003. Measurements of the concentration and composition of nuclei for cirrus formation. Proc. Natl. Acad. Soc. 100: $14655-14660$

Dobbie S, Jonas PR. 2001. Radiative influences on the structure and lifetime of cirrus clouds. Q. J. R. Meteorol. Soc. 127: 2663-2682.

ECMWF. 2004. 'IFS Documentation Cycle 28r1', Chapter IV: Physical processes, European Centre for Medium Range Weather Forecasts: Reading, UK. Available online: http://www.ecmwf.int/research/ifsdocs.

Field PR, Hogan RJ, Brown PRA, Illingworth AJ, Choularton TW, Cotton RJ. 2005. Parametrization of ice-particle size distributions for mid-latitude stratiform cloud. Q. J. R. Meteorol. Soc. 131: 1997-2017.

Fu Q, Carlin B, Mace G. 2000. Cirrus horizontal inhomogeneity and OLR bias. Geophys. Res. Lett. 27: 3341-3344.

Gary BL. 2006. Mesoscale temperature fluctuations in the stratosphere. Atmos. Chem. Phys. 6: 4577-4589.

Gayet J-F, Auriol F, Minikin A, Ström J, Seifert M, Krejci R, Petzold A, Febvre G, Schumann U. 2002. Quantitative measurement of the microphysical and optical properties of cirrus clouds with four different in situ probes: Evidence of small ice crystals. Geophys. Res. Lett. 29: 2230, doi:10.1029/2001GL014324.

Gayet J-F, Ovarlez J, Shcherbakov V, Ström J, Schumann U, Minikin A, Auriol F, Petzold A, Monier M. 2004. Cirrus cloud microphysical and optical properties at southern and northern midlatitudes during the INCA experiment. J. Geophys. Res. 109: D20206, doi:10.1029/2004JD004803.

Gayet J-F, Shcherbakov V, Mannstein H, Minikin A, Schumann U, Ström J, Petzold A, Ovarlez J, Immler F. 2006. Microphysical and optical properties of mid-latitude cirrus clouds observed in the southern hemisphere during INCA. Q. J. R. Meteorol. Soc. 132: 2719-2748.

Gierens K, Schumann U, Helten M, Smit H, Marenco A. 1999. A distribution law for relative humidity in the upper troposphere and lower stratosphere derived from three years of MOZAIC measurements. Ann. Geophys. 17: 1218-1226.

Gierens K, Kohlhepp R, Dotzek N, Smit HGJ. 2007. Instantaneous fluctuations of temperature and moisture in the upper troposphere and tropopause region. Part 1: Probability densities and their variability. Meteorol. Z. 16: 221-231.

Gettelman A, Kinnison DE. 2007. The global impact of supersaturation in a coupled chemistry-climate model. Atmos. Chem. Phys. 7: 1629-1643.

Gettelman A, Fetzer EJ, Eldering A, Irion FW. 2006. The global distribution of supersaturation in the upper troposphere from the Atmospheric Infrared Sounder. J. Climate 19: 6089-6103.

Grabowski WW. 2006. Sixth WMO International Cloud Modeling Workshop. Bull. Am. Meteorol. Soc. 87: 639-642.

Gregory D, Morcrette JJ, Jakob C, Beljaars ACM, Stockdale T. 2000. Revision of convection, radiation and cloud schemes in the ECMWF Integrated Forecast System. Q. J. R. Meteorol. Soc. 126: 1685-1710.
Gregory D, Wilson D, Bushell A. 2002. Insights into cloud parametrization provided by a prognostic approach. $Q$. J. $R$. Meteorol. Soc. 128: 1485-1504.

$\mathrm{Gu}$ Y, Liou KN. 2006. Cirrus cloud horizontal and vertical inhomogeneity effects in a GCM. Meteorol. Atmos. Phys. 91: 223-235.

Haag W, Kärcher B. 2004. The impact of aerosols and gravity waves on cirrus clouds at midlatitudes. J. Geophys. Res. 109: D12202, doi:10.1029/2004JD004579.

Haag W, Kärcher B, Ström J, Minikin A, Lohmann U, Ovarlez J, Stohl A. 2003. Freezing thresholds and cirrus cloud formation mechanisms inferred from in situ measurements of relative humidity. Atmos. Chem. Phys. 3: 1791-1806.

Hall WD, Pruppacher HR. 1976. The survival of ice particles falling from cirrus clouds in subsaturated air. J. Atmos. Sci. 33: 1995-2006.

Harrington JY, Meyers MP, Walko RL, Cotton WR. 1995. Parameterization of ice crystal conversion processes due to vapor deposition for mesoscale models using double-moment basis functions. Part I: Basic formulation and parcel model results. J. Atmos. Sci. 52 4344-4366.

Hartmann DL, Michelsen ML. 2002. No evidence for iris. Bull. Am. Meteorol. Soc. 83: 249-254.

Herzegh PH, Hobbs PV. 1980. The mesoscale and microscale structure and organization of clouds and precipitation in midlatitude cyclones. II: Warm frontal clouds. J. Atmos. Sci. 37: 597-611.

Heymsfield AJ, McFarquhar GM. 1996. High albedos of cirrus in the tropical Pacific warm pool: Microphysical interpretations from CEPEX and from Kwajalein, Marshall Islands. J. Atmos. Sci. $\mathbf{5 3}$ 2424-2451.

Heymsfield AJ, Miloshevich LM, Twohy C, Sachse G, Oltmans S. 1998. Upper-tropospheric relative humidity observations and implications for cirrus ice nucleation. Geophys. Res. Lett. 25: 1343-1346.

Holton JR, Gettelman A. 2001. Horizontal transport and the dehydration of the stratosphere. Geophys. Res. Lett. 28: 2799-2802.

Hoyle CR, Luo BP, Peter T. 2005. The origin of high ice crystal number densities in cirrus clouds. J. Atmos. Sci. 62: 2568-2579.

Ivanova D, Mitchell DL, Arnott WP, Poellot M. 2001. A GCM parameterization for bimodal size spectra and ice mass removal rates in mid-latitude cirrus clouds. Atmos. Res. 59-60: 89-113.

Jakob C. 2000. 'The representation of cloud cover in atmospheric general circulation models'. PhD thesis, University of Munich.

Jensen EJ, Pfister L. 2004. Transport and freeze-drying in the tropical tropopause layer. J. Geophys. Res. 109: D02207, doi: 10.1029/2003JD004022.

Jensen EJ, Toon OB, Vay SA, Ovarlez J, May R, Bui P, Twohy CH, Gandrud B, Pueschel RF, Schumann U. 2001. Prevalence of ice-supersaturated regions in the upper troposphere: Implications for optically thin ice cloud formation. J. Geophys. Res. 106: 17253-17266.

Kärcher B, Haag W. 2004. Factors controlling upper tropospheric relative humidity. Ann. Geophys. 22: 705-715.

Kärcher B, Lohmann U. 2002. A parameterization of cirrus cloud formation: Homogeneous freezing including effects of aerosol size. J. Geophys. Res. 107: 4698, doi: 10.1029/2001JD001429.

Kärcher B, Ström J. 2003. The roles of dynamical variability and aerosols in cirrus cloud formation. Atmos. Chem. Phys. 3: 823-838.

Kärcher B, Voigt C. 2006. Formation of nitric acid/water ice particles in cirrus clouds. Geophys. Res. Lett. 33: L08806, doi: 10.1029/2006GL025927.

Kärcher B, Hendricks J, Lohmann U. 2006. Physically based parameterization of cirrus cloud formation for use in global atmospheric models. J. Geophys. Res. 111: D01205, doi: 10.1029/2005JD006219.

Köhler M. 1999. 'Explicit prediction of ice clouds in general circulation models'. PhD thesis, University of California at Los Angeles.

Koop T, Luo BP, Tsias A, Peter T. 2000. Water activity as the determinant for homogeneous ice nucleation in aqueous solutions. Nature 406: 611-614.

Lacis AA, Wuebbles DJ, Logan JA. 1990. Radiative forcing of climate by changes in the vertical distribution of ozone. J. Geophys. Res. 95: 9971-9981.

Larson VE. 2004. Prognostic equations for cloud fraction and liquid water and their relation to filtered density functions. J. Atmos. Sci. 61: $338-351$.

Law K, Pan L, Wernli H, Fischer H, Haynes P, Salawitch R, Kärcher B, Prather M, Doherty S, Ravishankara AR. 2006. 'Processes governing 
the chemical composition of the extra-tropical UTLS'. SPARC Newsletter No. 26, 8-19.

Lawson RP, Baker B, Pilson B, Mo Q. 2006. In situ observations of the microphysical properties of wave, cirrus, and anvil clouds. Part II: Cirrus clouds. J. Atmos. Sci. 63: 3186-3203.

Lindzen RS, Chou M-D, Hou AY. 2001. Does the earth have an adaptive infrared iris? Bull. Am. Meteorol. Soc. 82: 417-432.

Liu X, Penner JE, Ghan S-J, Wang M. 2007. Inclusion of ice microphysics in the NCAR Community Atmospheric Model Version 3 (CAM3) J. Climate 20: 4526-4547.

Lohmann U, Kärcher B. 2002. First interactive simulations of cirrus clouds formed by homogeneous freezing in the ECHAM GCM J. Geophys. Res. 107: 4105, doi: 10.1029/2001JD000767.

Lohmann U, Kärcher B, Hendricks J. 2004. Sensitivity studies of cirrus clouds formed by heterogeneous freezing in the ECHAM GCM J. Geophys. Res. 109: D16204, doi: 10.1029/2003JD004443.

Mace GG, Clothiaux EE, Ackerman TP. 2001. The composite characteristics of cirrus clouds: Bulk properties revealed by one year of continuous cloud radar data. J. Climate 14: 2185-2203.

McFarquhar GM, Heymsfield AJ, Spinhirne J, Hart B. 2000. Thin and subvisual tropopause tropical cirrus: Observations and radiative impacts. J. Atmos. Sci. 57: 1841-1853.

Miloshevich LM, Heymsfield AJ. 1997. A balloon-borne continuous cloud particle replicator for measuring vertical profiles of cloud microphysical properties: Instrument design, performance, and collection efficiency analysis. J. Atmos. Oceanic Technol. 14: 753-768.

Möhler O, Stetzer S, Schaefers S, Linke C, Schnaiter M, Tiede R, Saathoff H, Krämer M, Mangold A, Budz P, Zink P, Schreiner J, Mauersberger K, Haag W, Kärcher B, Schurath U. 2003. Experimental investigations of homogeneous freezing of sulphuric acid particles in the aerosol chamber AIDA. Atmos. Chem. Phys. 3: 211-223.

Murphy DM, Koop T. 2005. Review of the vapour pressures of supercooled water for atmospheric applications. Q.J. R. Meteorol. Soc. 131: 1539-1565.

Ou S-C, Liou K-N. 1995. Ice microphysics and climatic temperature feedback. Atmos. Res. 35: 127-138.

Ovarlez J, Gayet J-F, Gierens K, Ström J, Ovarlez H, Auriol F, Busen R, Schumann U. 2002. Water vapour measurements inside cirrus clouds in Northern and Southern Hemispheres during INCA Geophys. Res. Lett. 29: 1813, doi: 10.1029/2001GL014440.

Peter T, Marcolli C, Spichtinger P, Corti T, Baker MB, Koop T. 2006 When dry air is too humid. Science 314: 1399-1402.

Pincus R, Klein SA. 2000. Unresolved spatial variability and microphysical process rates in large-scale models. J. Geophys. Res. $\mathbf{1 0 5}$ 27059-27065.

Pincus R, Barker HW, Morcrette J-J. 2003. A fast, flexible, approximate technique for computing radiative transfer in inhomogeneous cloud fields. J. Geophys. Res. 108: 4376, doi: 10.1029/2002JD003322

Quante M, Starr DO'C. 2002. Dynamical processes in cirrus clouds Pp. 346-374 in Cirrus. Lynch DK, Sassen K, Starr DO'C, Stevens G. (eds.) Oxford University Press: Oxford and New York.

Rasch PJ, Kristjànnson JE. 1998. A comparison of the CCM3 model climate using diagnosed and predicted condensate parameterizations. J. Climate 11: 1587-1614.

Ren C, MacKenzie AR. 2005. Cirrus parameterization and the role of ice nuclei. Q. J. R. Meteorol. Soc. 131: 1585-1605.

Ricard JL, Royer JF. 1993. A statistical cloud scheme for use in an AGCM. Ann. Geophys. 11: 1095-1115.

Ringer MA, McAvaney BJ, Andronova N, Buja LE, Esch M, Ingram WJ, Li B, Quaas J, Roeckner E, Senior CA, Soden BJ, Volodin EM, Webb MJ, Williams KD. 2006. Global mean cloud feedbacks in idealized climate change experiments. Geophys. Res. Lett. 33: L07718, doi: 10.1029/2005GL025370.

Sassen K, Starr DO'C, Uttal T. 1989. Mesoscale and microscale structure of cirrus clouds: Three case studies. J. Atmos. Sci. 46 371-396.

Smith RNB. 1990. A scheme for predicting layer clouds and their water content in a general circulation model. Q. J. R. Meteorol. Soc. 116 $435-460$.
Sommeria G, Deardorff JW. 1977. Subgrid-scale condensation in models of nonprecipitating clouds. J. Atmos. Sci. 34: 344-355.

Spichtinger P, Gierens K, Read W. 2003. The global distribution of ice-supersaturated regions as seen by the Microwave Limb Sounder. Q. J. R. Meteorol. Soc. 129: 3391-3410.

Starr DO'C, Cox SK. 1985. Cirrus clouds, Part II: Numerical experiments on the formation and maintenance of cirrus. J. Atmos. Sci. 42: 2682-2694.

Stephens GL, Tsay S-C, Stackhouse PW, Flatau PJ. 1990. The relevance of the microphysical and radiative properties of cirrus clouds to climate and climatic feedback. J. Atmos. Sci. 47: 1742-1753.

Ström J, Strauss B, Anderson T, Schröder F, Heintzenberg J, Wendling P. 1997. In-situ observations of the microphysical properties of young cirrus clouds. J. Atmos. Sci. 54: 2542-2553.

Ström J, Seifert M, Kärcher B, Ovarlez J, Minikin A, Gayet J-F, Krejci R, Petzold A, Auriol F, Haag W, Busen R, Schumann U, Hansson HC. 2003. Cirrus cloud occurrence as a function of ambient relative humidity: A comparison of observations obtained during the INCA experiment. Atmos. Chem. Phys. 3: 1807-1816.

Sundqvist H, Berge E, Kristjánsson JE. 1989. Condensation and cloud parameterization studies with a mesoscale numerical weather prediction model. Mon. Weather Rev. 117: 1641-1657.

Teixeira J. 2001. Cloud fraction and relative humidity in a prognostic cloud fraction scheme. Mon. Weather Rev. 129: 1750-1753.

Thornton BF, Toohey DW, Tuck AF, Elkins JW, Kelly KK, Hovde SJ, Richard EC, Rosenlof K, Thompson TL, Mahoney MJ, Wilson JC. 2007. Chlorine activation near the midlatitude tropopause. J. Geophys. Res. 112: D18306, doi: 10.1029/2006JD007640.

Tiedtke M. 1993. Representation of clouds in large-scale models. Mon. Weather Rev. 121: 3040-3061.

Tompkins AM. 2002. A prognostic parameterization for the subgridscale variability of water vapor and clouds in large-scale models and its use to diagnose cloud cover. J. Atmos. Sci. 59: 1917-1942.

Tompkins AM. 2003. Impact of temperature and total water variability on cloud cover assessed using aircraft data. Q. J. R. Meteorol. Soc. 129: $2151-2170$.

Tompkins AM, Gierens K, Rädel G. 2007. Ice supersaturation in the ECMWF integrated forecast system. Q. J. R. Meteorol. Soc. 133: 53-63.

Udelhofen PM, Hartmann DL. 1995. Influence of tropical cloud systems on the relative humidity in the upper troposphere. J. Geophys. Res. 100: 7423-7440.

Walcek CJ. 1992. 'Extrapolating cloud-scale microphysical, dynamic and radiative processes to global and climatic scales: How accurately do we know the fractional area of cloud coverage?'. WMO Cloud Microphysics and Applications to Global Climate Change Workshop, 10-14 August 1992, Toronto, Canada.

Whiteway J, Cook C, Gallagher M, Choularton T, Harries J, Connolly P, Busen R, Bower K, Flynn M, May P, Aspey R, Hacker J. 2004. Anatomy of cirrus clouds: Results from the Emerald airborne campaigns. Geophys. Res. Lett. 31: L24102, doi: 10.1029/2004GL02101.

Wood R, Field PR. 2000. Relationships between total water, condensed water, and cloud fraction in stratiform clouds examined using aircraft data. J. Atmos. Sci. 57: 1888-1905.

Yang P, Liou K-N, Wyser K, Mitchell D. 2000. Parameterization of the scattering and absorption properties of individual ice crystals. J. Geophys. Res. 105: 4699-4718.

Yang P, Wei H, Huang H-L, Baum BA, Hu YX, Kattawar GW, Mishchenko MI, Fu Q. 2005. Scattering and absorption property database for nonspherical ice particles in the near- through farinfrared spectral region. Appl. Opt. 44: 5512-5523.

Zhang MH, Lin WY, Klein SA, Bacmeister JT, Bony S, Cederwall RT, DelGenio AD, Hack JJ, Loeb NG, Lohmann U, Minnis P, Musat I, Pincus R, Stier P, Suarez MJ, Webb MJ, Wu JB, Xie SC, Yao M-S, Zhang JH. 2005. Comparing clouds and their seasonal variations in 10 atmospheric general circulation models with satellite measurements. J. Geophys. Res. 110: D15S02, doi: 10.1029/2004JD005021. 